NBER WORKING PAPER SERIES

\title{
EFFECTIVE POLICY FOR REDUCING INEQUALITY? THE EARNED INCOME TAX CREDIT AND THE DISTRIBUTION OF INCOME
}

\author{
Hilary W. Hoynes \\ Ankur J. Patel \\ Working Paper 21340 \\ http://www.nber.org/papers/w21340 \\ NATIONAL BUREAU OF ECONOMIC RESEARCH \\ 1050 Massachusetts Avenue \\ Cambridge, MA 02138 \\ July 2015
}

The authors thank Day Manoli and Jesse Rothstein for helpful conversations as well as participants at Montana State and Berkeley Demography Brown Bag. This research represents our private research efforts and does not necessarily reflect the views or opinions of the U.S. Department of the Treasury. The views expressed herein are those of the authors and do not necessarily reflect the views of the National Bureau of Economic Research.

NBER working papers are circulated for discussion and comment purposes. They have not been peerreviewed or been subject to the review by the NBER Board of Directors that accompanies official NBER publications.

(C) 2015 by Hilary W. Hoynes and Ankur J. Patel. All rights reserved. Short sections of text, not to exceed two paragraphs, may be quoted without explicit permission provided that full credit, including (C) notice, is given to the source. 
Effective Policy for Reducing Inequality? The Earned Income Tax Credit and the Distribution of Income Hilary W. Hoynes and Ankur J. Patel

NBER Working Paper No. 21340

July 2015

JEL No. H2,I38,J2

\begin{abstract}
In this paper, we examine the effect of the EITC on the employment and income of single mothers with children. We provide the first comprehensive estimates of this central safety net policy on the full distribution of after-tax and transfer income. We use a quasi-experiment approach, using variation in generosity due to policy expansions across tax years and family sizes. Our results show that a policyinduced $\$ 1000$ increase in the EITC leads to a 7.3 percentage point increase in employment and a 9.4 percentage point reduction in the share of families with after-tax and transfer income below 100\% poverty. Event study estimates show no evidence of differential pre-trends, providing strong evidence in support of our research design. We find that the income increasing effects of the EITC are concentrated between $75 \%$ and $150 \%$ of income-to-poverty with little effect at the lowest income levels (50\% poverty and below) and at levels of $250 \%$ of poverty and higher. By capturing the indirect effects of the credit on earnings, our results show that static calculations of the anti-poverty effects of the EITC (such as those released based on the Supplemental Poverty Measure, Short 2014) may be underestimated by as much as 50 percent.
\end{abstract}

Hilary W. Hoynes

Richard \& Rhoda Goldman School of Public Policy University of California, Berkeley

2607 Hearst Avenue

Berkeley, CA 94720-7320

and NBER

hoynes@berkeley.edu

Ankur J. Patel

Department of the Treasury

Ankur.Patel@treasury.gov 


\section{Introduction}

Since the mid-1970s, earnings for less skilled workers have stagnated (Autor 2014). Hourly wages for men with less than a high school degree have fallen in real terms by more than 20 percent since 1973. Declines, though of a smaller degree, have occurred for men with a high school degree and for those with some college. Real wages for women with a high school degree or some college show smalls gains, though high school dropouts have seen no real increases. These factors combine to show losses or no change in real family income for the bottom 20 percent of the population (Mishel et al 2012). This is particularly salient given the high and persistent premium paid to college educated workers (Autor 2014) and the steady gains in income held by the top one percent of taxpayers (Piketty and Saez 2003).

Given this backdrop of stagnating wages and income for lower income Americans, there is a renewed interest in policies aimed at reducing inequality and increasing income and opportunity of the less advantaged population. At the same time, there is also concern about the related problem of secular declines in employment rates among prime aged men, and more recently, women (Economic Report of the President 2015). Commonly mentioned policies include raising minimum wages, increasing the Earned Income Tax Credit, and pre-market interventions aimed at increasing human capital and skills.

In this paper, we comprehensively evaluate the central "post-market" policy aimed at the twin concerns of stagnant earnings and low employment - the Earned Income Tax Credit (EITC). In particular, we use a quasi-experimental research design to comprehensively estimate the effect of the EITC on the distribution of after-tax and transfer income. We are the first paper to examine the degree to which the large expansions in the federal EITC increases income, and where in the income distribution these changes occur. Our approach captures three central 
channels through which the EITC may affect after-tax income. We capture the direct effect of the tax payment (the "credit" effect) as well as the indirect effect of increasing earnings (the "earnings" effect) as well as any reduction in other public assistance (or other) income (the “income adjustment" effect). ${ }^{1}$

The EITC provides a refundable tax credit to lower income working families. Tax expansions over the past two decades have made the EITC a central element of the U.S. safety net (Bitler, Hoynes and Kuka 2014). In 2012, the EITC reached 28 million tax filers at a total cost of $\$ 64$ billion, with an average credit amount of $\$ 2,970$ for families with children (Internal Review Service 2014). Almost 20 percent of all tax filers and 44 percent of filers with children receive the EITC. In contrast, fewer than 2 million families received cash welfare benefits (TANF) in 2011, a 62 percent decline since 1994.

Given the prominence of the EITC in the U.S. safety net, it is not surprising that many studies have evaluated its effects. We have two decades of research on the effect of the EITC on labor supply (see reviews by Hotz and Scholz 2003, Eissa and Hoynes 2006, Nichols and Rothstein 2015). The evidence shows that the EITC leads to substantial increases in employment for single parent families with children and small reductions in employment for secondary earners in married couples (e.g., Eissa and Liebman 1996, Meyer and Rosenbaum 2000, 2001, Eissa and Hoynes 2004). There is less evidence on the intensive margin of labor supply, though some studies show that workers adjust to maximize the credit along the phase-in region (Chetty, Friedman and Saez 2013, Saez 2010, Chetty and Saez 2013). There is a recent, and growing, literature leveraging the presumed gains in family resources that are generated by the EITC and finds that the credit leads to increases in infant health (Baker 2008, Baughman 2012, Hoynes,

\footnotetext{
${ }^{1}$ In theory, the reduction in other income may exceed the increase in earnings, leading to a reduction in pre-tax income.
} 
Miller and Simon 2015, Strully et al 2010), maternal health (Evans and Garthwaite 2014), children's cognitive outcomes (Dahl and Lochner 2012, Chetty, Friedman, and Rockoff 2011) and educational attainment (Michelmore 2013, Manoli and Turner 2014).

Despite its importance, we know much less about the effect of the EITC on the distribution of income. Calculations based on the Supplemental Poverty Measure show that the EITC (together with the child tax credit) removed 4.7 million children from poverty in 2013 (Short 2014), making the EITC the largest anti-poverty program for children in the U.S. ${ }^{2}$ This estimate is a static calculation, constructed by zeroing out observed EITC income and recalculating poverty; thus capturing only the direct credit effect (and not the indirect effects of earnings and other income). Incorporating the effect of the credit on earnings is expected to lead to larger poverty reductions. This static or simulation approach has also been used by Liebman (1998) and Meyer (2010).

A handful of studies estimate the effect of the EITC on earnings (e.g., Grogger 2003, Newmark and Wascher 2001, 2011) and income or poverty (Bollinger et al 2009, Grogger 2003, Gunderson and Ziliak 2004). We expand on these studies in four ways. First, we focus on the federal credit while many of the others focus on the much smaller state EITCs. ${ }^{3}$ Second, we comprehensively examine the effects across the distribution of family after tax and transfer income relative to poverty. Third, we exploit tax-policy-driven differences between women without children compared to those with children as well as differences across women with one versus two or more children. Finally, we present event study models to evaluate the validity of the quasi-experimental approach. The result is a full picture of the antipoverty effects of the program.

\footnotetext{
${ }^{2}$ The next largest is SNAP, which removed 2.1 million children from poverty in 2013.

${ }^{3}$ In addition, the timing of state introduction and expansions of EITCs may not be exogenous. State legislation is typically passed in times of strong labor markets and healthy state revenues.
} 
Our main results leverage the significant variation in the 1993 expansion of the credit across family size (as first presented in Eissa and Liebman 1996), by employing a difference-indifference and an event study approach. We extend that analysis in a parameterized differencein-difference approach that takes advantage of credit expansions over the longer period 19841998. Both approaches leverage variation across family size and tax year. A second contribution of our analysis is to update the existing literature on the employment effects of the EITC. As with our analysis of the distribution of income, our main results use the 1993 EITC expansion in a difference-in-difference and event study framework. We also present results that utilize the multiple reforms over the full sample period. ${ }^{4}$

Throughout our analysis, we focus on single women, who have the largest participation rates in the program. In particular we use the Current Population Survey and our sample consists of single women age 24-48 whose educational attainment is some college or less. Single filers with children account for almost 60 percent of EITC filers and about three-quarters of the cost of the credit. We find that the 1993 expansion of the credit led to a 6.1 percentage point increase in the employment of single mothers, which is large relative to the mean employment rate of 84 percent. These effects translate to a 7.3 percentage point increase per $\$ 1000$ of EITC, and an extensive margin elasticity of 0.36 . We find that the 1993 expansion led to a 7.9 percentage point decrease in the share with after tax and transfer income below poverty (for families headed by these single women) implying a 9.4 percentage point effect per $\$ 1000$ in federal EITC. A fuller analysis across the distribution of income shows that the income-increasing effects of the EITC are concentrated between $75 \%$ and $150 \%$ of the federal poverty threshold. Importantly, we find

\footnotetext{
${ }^{4}$ Our work updates Meyer and Rosenbaum (2000) who estimate event study models of employment for single women with children in the 1990s.
} 
that the static calculations of the effects of the EITC underestimate the anti-poverty effects of the credit by up to 50 percent.

These results are robust to several alternative specifications including whether or not we include a conservative set of controls, whether we use variation across single women with no children versus those with children or single women with one versus two or more children, and whether we use the sharp change in 1993 or the full set of EITC expansions back to 1984. Finally, our event study graphs provide compelling evidence that the research design comparing outcomes across different family sizes - is valid.

Our paper also contributes to the broader literature on the effects of social policies on the distribution of income. Many studies have used the extensive variation in minimum wages across states to examine the effects on inequality and the distribution of income (for example see Burkhauser and Sabia 2007, Card and Krueger 1995, Dube 2013, Gunderson and Ziliak 2004, and Neumark et al 2005 as well as reviews in Autor et al 2010, Dube 2013, and Nuemark and Wascher 2008). Fransden (2012) estimates the effects of unionization on the distribution of earnings. Havnes and Mogstad (2015) estimate the effect of universal child care on the distribution of income. It is worth pointing out that many of these studies estimate the effects on inequality such as the ratio of the median to the $10^{\text {th }}$ percentile of family income (P50/P10). This reveals the effect of minimum wages on relative incomes - capturing lower tail inequality. This relative approach does not lend itself to our analysis, because our research design uses variation across family size (and tax year) and inequality within demographic groups are not the object of interest. Instead we focus on absolute changes in income, capturing how the EITC affects the share or number of families with incomes above various thresholds in the distribution. 
In the following section we describe the EITC and its evolution. In section 3, we explore the incentives created by the EITC on employment and across the income distribution. The dataset is presented in section 4 (also see data appendix), and we detail our estimation strategy in section 5. In section 6 we present our estimates of the effect of the EITC on employment and on the distribution of after tax and transfer income. We use the estimates from section 6 to calculate the effects of the EITC on the aggregate number of individuals and children in poverty in section 7 , and we conclude with section 8 .

\section{The Earned Income Tax Credit}

A taxpayer may claim the EITC on a federal income tax return. To be eligible for the EITC, a taxpayer must have earned income during the tax year. ${ }^{5}$ Taxpayers must have less than a specified amount of adjusted gross income (AGI) and earned income. The value of the credit is determined by a benefit schedule that generally has three regions. In the phase-in region, the credit increases by a share of each additional dollar earned. Once the credit reaches its maximum (capped) value, the taxpayer is in the second "flat" region. In the final region, the credit is phased-out with each additional dollar of AGI until it is zero. There are separate schedules, with the same basic shape, by filing status and by the number of qualifying children claimed. ${ }^{6}$ Figure 1 displays the schedule in 2013 (as a function of earned income) for single taxpayers with no, one, two, and three or more children. The phase-in or subsidy rate is substantial at 34 (40) percent for those with one (two) children. The phase-out rate is much lower at 15.98 (21.06) percent for those with one (two) children. The maximum allowable income for a taxpayer with

\footnotetext{
${ }^{5}$ Earned income is the sum of wages, tips, salary, union strike benefits, some disability payments, and net selfemployment earnings (IRS 2013).

${ }^{6}$ A qualifying child is younger than 19 (or younger than 24 and a full time student), lives with the taxpayer for more than half the year, has a valid social security number, and is not claimed as a dependent by another taxpayer (IRS 2013).
} 
one child (two or more children) was $\$ 37,870(\$ 43,038)$. The maximum benefit differs substantially across number of children, from $\$ 487$ for those without children to $\$ 6,044$ for those with three or more children. Finally, the credit is refundable: if the credit exceeds a taxpayer's tax liability, they receive the difference as refund.

These eligibility rules target working families who are relatively low in the income distribution. This can be observed empirically. Using the Statistics of Income Complete Report File for 2011, Table 1 presents data on the distribution of EITC filers by income-to-poverty bins. We define after-tax income as gross taxable income less taxes owed plus credits and apply this to the official poverty thresholds using the family size of the tax filing unit. The top panel of Table 1 shows the distribution of filers separately by marital status and number of children. The majority of single taxpayers who claim the EITC are between $50 \%$ and $150 \%$ of the federal poverty threshold. ${ }^{7}$ For example, 25 percent of single EITC recipients with one child have net income between 50 and 100 percent of poverty $(\$ 7,752-\$ 15,504$ in 2011) while another 29 percent have net income between 100 and 150 percent of poverty $(\$ 15,505-\$ 23,256$ in 2011). EITC filers with two children, and those filing a joint return (e.g. married), have higher income levels. For example, 19 percent of married EITC filers with one child have income between 50 and 100 percent poverty $(\$ 9,053-\$ 18,106)$ and another 25 percent have income between 100 and $150 \%$ of poverty. Fully half have incomes beyond that point. The bottom panel of Table 1 displays the share of filers who claim the EITC by multiples of the federal poverty threshold. A large share of filers receive the EITC - for example 62 (73) percent of single filers with one (two or more) children and 19 (22) percent of married couples with one (two or more) children. The

\footnotetext{
${ }^{7}$ Liebman (1998) finds a similar result using the 1993 CPS with EITC rules from 1996. He contrasts this with traditional welfare (AFDC and Food Stamps), which are targeted at families with lower multiples of the poverty threshold.
} 
vast majority of filers claim the EITC below 2 times the federal poverty threshold. Overall, the EITC eligibility rules accomplish a transfer for those who have relatively low income.

The EITC schedule has been expanded several times since its inception in 1975. Figure 2 illustrates the changes over time by plotting the maximum credit amount by tax year and number of qualified children (in real 2013 dollars). Figure 2 also identifies the four tax reforms responsible for these changes. ${ }^{8}$ The 1993 legislation produced the most dramatic changes to the policy, increasing the benefit for those with any children as well as for those with two or more children relative to those with one child. In contrast to tax year 1984, families claiming two or more children in tax year 1997 enjoyed an increase in the maximum credit of $\$ 4,236$ (2013 dollars). Eligible families with one child experienced a smaller increase of $\$ 2,111$. Finally, there were smaller increases for those without children (\$488, OBRA 93) and those with three or more children (\$670, ARRA 2009). We use differential expansions across family size over time as the basis of our quasi-experimental design.

In addition to the EITC, there were other changes to tax and transfer policy during this period. Those eligible for the federal EITC also saw changes to their federal exemptions, and to their tax bracket rates and thresholds. These families would also be eligible for an increasing number of state-level EITCs. ${ }^{9}$ At the same time, traditional welfare benefits for families with children were curtailed (e.g., Moffitt 2003, Ziliak 2015). For example, states introduced changes to the Aid to Families with Dependent Children (AFDC) program through federally-approved waivers. These waivers allowed states to introduce various provisions aimed at reducing AFDC

\footnotetext{
${ }^{8}$ The four tax reforms are the Tax Reform Act of 1986 (TRA 86), the Omnibus Budget Reconciliation Acts of 1990 \& 1993 (OBRA 90 \& OBRA 93), and the American Recovery and Reinvestment Act of 2009 (ARRA 2009). In addition, the flat and phase-out regions were extended for married couples in the Economic Growth and Tax Relief Reconciliation Act of 2001.

${ }^{9}$ Currently, 28 states including DC have an earned income tax credit (IRS 2014).
} 
participation and enabling the transition from welfare to work. ${ }^{10}$ In 1996 , many of these benefit limits were introduced nationally with the Temporary Assistance for Needy Families (TANF) program, which also restricted the amount of federal funding available to states (Crouse 1999). In the empirical specification below, we control for these changes in other tax and transfer programs to isolate the effects of the EITC.

The evolution of these policies increased the relative importance of the EITC as an income support program. Figure 3 displays per capita expenditures for the EITC, the AFDC program, the TANF program and the Supplemental Nutrition Assistance Program (SNAP) ${ }^{11}$ (Bitler and Hoynes 2010). Prior to 1986, per capita spending on the EITC was only a fraction of other welfare programs. After welfare reform, and even through the Great Recession, spending on the EITC was much larger than that on TANF cash grants.

\section{The EITC, Employment and the Distribution of Income}

The EITC generates labor supply incentives on the intensive and extensive margins and may differ depending on marital status. Among single parents, who represent the focus of our analysis, the EITC (overall or an expansion in the credit) increases the returns to entering employment for those outside of the labor force - leading to an increase in the extensive margin of labor supply. The effects of the EITC on the intensive margin, for those already in the labor market, are less unambiguously work-promoting. In the phase-in region, the net-of-tax wage increases with the EITC; the effect on the intensive margin is ambiguous due to a positive substitution effect and a negative income effect. On the other hand, in the phase-out region, both

\footnotetext{
${ }^{10}$ Changes to AFDC through waivers include work and training requirements, time limits on welfare receipt, family caps provisions, expanded income disregards, increased resource limits, Medicaid assistance for the transition to work, expanded eligibility for two-parent families, and improved child support enforcement (HHS 1997).

${ }^{11}$ SNAP was formerly called the Food Stamps Program.
} 
substitution and income effects create a consistent incentive to reduce labor supply (in the flat region the pure income effect also is predicted to reduce labor supply).

Because the EITC is based on family income, the credit leads to a somewhat different set of incentives for married taxpayers. Overall, as with singles, we would expect higher rates of "family" employment for married couples, as a result of the credit being tied to work. Among secondary earners, though, the EITC is expected to reduce labor supply due to the increased after-tax income (and additional tax due to the phase-out rate) generated by the EITC schedule and the primary earner's labor supply (Eissa and Hoynes 2004).

Most studies focus on single mothers, the group that forms the largest share of EITC recipients (three quarters of EITC payments go to head of household [single with children] filers). A large body of empirical work has found that the EITC increases labor supply on the extensive margin among single women with children. ${ }^{12}$ For example, Eissa and Liebman (1996) find labor force participation increased by 2.8 percentage points for single females with children, relative to single females without children after the EITC expansion of 1986. Meyer and Rosenbaum (2001) find that the EITC raised labor force participation increased by 7.2 percentage points for single women with children relative to those without children between 1984 and 1996. Chetty, Guren, Manoli and Weber (2013) calculate the extensive margin elasticities for these studies to be 0.30 and 0.43 respectively. Chetty, Friedman and Saez (2013) examine the effect of the EITC on the intensive margin. They find an increase in labor supply for those in the phase-in region, but do not find a decrease in labor supply for those in the phase-out region.

\footnotetext{
12 Detailed surveys can be found in Hotz and Scholz (2003), Eissa and Hoynes (2006), and Nichols and Rothstein (2015). More recent work includes Gelber and Mitchell (2012).
} 
The expected effect of the EITC on after-tax and transfer income is complex (Liebman 1998, Grogger 2003, Bollinger, Gonzalez and Ziliak 2009, Meyer 2010, Hoynes, Miller and Simon 2015). For those induced by the EITC to enter the labor market, we expect after-tax and transfer (ATT) income to increase. There are three components to the change in ATT income. First, direct EITC payments increase income. Second, induced earnings increase pre-tax income. Third, the increased earnings may lead to reductions in other income sources. In particular, the likelihood that the same family qualifies for traditional welfare payments such as cash welfare (AFDC/TANF) and SNAP is expected to decrease (as earnings increases). We call these the credit effect, the earnings effect, and the income-adjustment effect.

For those already in the work force, the main channel for increasing ATT income is the credit effect. In principle, this positive credit effect could be offset by a negative earnings effect, to the extent to which worker's respond to the phase-out rate. However, given the lack of evidence of a behavioral response in the phase-out region, we don't expect the offset to be significant. Additionally, due to the shifting out of the labor supply curve induced by the EITC, market wages may decline as employers interact with increased labor supply on the extensive margin (Rothstein 2010); potentially then earnings at a fixed number of hours worked may decline.

As discussed above, and presented in Figure 1 and Table 1, the EITC schedule targets the largest credit to incomes around the poverty threshold. For example, for a single woman with two children, the flat region of the credit (where they receive the maximum credit) corresponds to earnings between 0.7 and 0.9 times the poverty threshold and the phase-out region extends to 2.3 times the poverty threshold. ${ }^{13}$ Accordingly, our prior is that the EITC is unlikely to effect the

\footnotetext{
${ }^{13}$ In 2014 , for a single woman with two children, the flat region corresponds to earnings $\$ 9,720-\$ 17,830$ and the phase-out extends to $\$ 38,511$. The poverty threshold for this family is $\$ 16,317$.
} 
very lowest incomes (where families have less connection to the labor market) nor those with incomes much beyond 200 percent of poverty.

Our approach, using a comprehensive measure of ATT income, allows us to capture the total effect of the EITC - the credit effect, the earnings effect, and the income adjustment effect. We do so by focusing on the largest group of recipients, single women with children. By exploiting large expansions in the credit, with a credible quasi-experimental design, we provide the first comprehensive analysis of the effect of the federal EITC on the distribution of income.

Our approach, described below, leverages variation across family size and tax year to identify the effects of the EITC (figure 1,2). This approach relies on the assumption that women are not changing their fertility in response to this incentive. There is significant evidence to support this assumption. Baughman and Dickert-Conlin (2009) find a small negative impact of the EITC on higher order fertility within a large sample of birth certificate data. Dickert-Conlin and Chandra (1999) find that the income tax may be correlated with the timing of childbirth, but only within a short window of a few weeks. Taken together, the evidence suggests that the EITC does little to modify fertility behavior.

\section{Data}

The primary dataset is the Current Population Survey March Annual Social and Economic Supplement (CPS). The CPS contains representative income and demographic information, making it appropriate for the study of labor supply and the distribution of income. We begin with the 1985-2014 surveys, corresponding to income over calendar years 1984-2013. We limit to single women between the ages of 24 and 48, who are not ill, disabled or going to school. We further limit the sample to those who have some college education or less (see data 
appendix for more details). Where possible we augment the CPS data with information on the universe of tax returns (the Statistics of Income Complete Report File). The tax data is not sufficient to provide the main data for our analysis, given that we need to capture safety net income (not captured in the tax data) and we need to capture movements into and out of the labor force (taxable universe).

We explore the impact of the EITC on different points of the income distribution using multiples of the official poverty threshold (50\% poverty, $100 \%$ poverty, $150 \%$ poverty, etc.). We use a comprehensive measure of after-tax and transfer (ATT) income defined as pre-tax cash income plus the cash value (as reported by the household or imputed by the Census Bureau) of non-cash programs (food stamps, school lunch, housing subsidies, and energy subsidies) and subtracts payroll taxes and nets out federal and state income taxes (including the EITC, child and child care tax credits, and stimulus payments). We then use the poverty thresholds that are the basis of official poverty, resulting in an after-tax and transfer income measure of poverty. Our income measure differs from official poverty in our inclusion of inkind transfers and taxes; it is similar to the Supplemental Poverty Measure and the earlier National Academy of Sciences recommendations (Citro and Michael 1995), but that we can measure consistently back to the mid-1980s where we begin our analysis. We have developed this measure in earlier work (Bitler and Hoynes 2010, 2014). ${ }^{14}$

While the CPS does collect information regarding income and transfers, it does not collect income tax information. We calculate taxes using income and demographics from the CPS using the NBER TAXSIM calculator (Feenberg and Coutts 1993). We first construct tax

\footnotetext{
${ }^{14}$ The main difference is that the SPM includes out of pocket medical costs and work expenses in its measure of after tax and transfer income. Additionally, the poverty threshold in the SPM in part reflects relative income amounts while we use the official poverty thresholds absolute measures. We make these changes to facilitate consistent measurement back to 1980 .
} 
units by linking each qualified child to his/her mother (if between 24 and 48), otherwise her youngest grandmother or great-grandmother between the ages of 24 and $48 .{ }^{15}$ For example, suppose a household contains 3 individuals: a 25 year old mother, her infant child, and the child's 47 year old grandmother. We define the 25 year old mother as the primary tax filer, with one eligible child. If instead the mother was 17 years old, then the 47 year old grandmother is assigned as the primary tax filer, with two EITC eligible children. Using these tax units, we use TAXSIM to calculate income and payroll taxes (see data appendix for details). The resulting measure of after-tax and transfer income is consistent over the sample period. ${ }^{16}$

Appendix Table 1 presents summary statistics by the presence of children. Single women with children differ from those without children (Eissa and Liebman 1996, Meyer and Rosenbaum 2001). Women without children have more education, are more likely to be white, are less likely to be divorced, and are more likely to be employed. Average earned income is higher for women without children, but after-tax and transfer income is higher for those with children. ${ }^{17}$ To better balance these two groups in our empirical specifications below, we include a rich set of demographic controls, as well as controls for policy changes and labor market conditions.

\section{Methods}

The differences-in-differences (DD) estimator is used extensively in the EITC literature to overcome endogeneity arising from the relationship between the EITC, labor supply and unobserved correlates (Eissa and Liebman 1996, Meyer and Rosenbaum 2000, Hotz and Scholz

\footnotetext{
${ }^{15}$ IPUMS provides information on the relationship of between children and adults in the household (see data appendix for more details).

${ }^{16}$ Meyer, Mok and Sullivan (2008) note that observed income values in the CPS have deteriorated over time relative to administrative aggregates.

${ }^{17}$ See section 6 for statistics by tax year.
} 
2003, Eissa and Hoynes 2006). The DD estimator compares a treatment group to a control group, before and after a legislative change in the EITC. The control group captures common changes across the timing of the legislation. We use the following DD specification to examine the largest of the expansions, OBRA 93 (figure 2), in a transparent way,

$$
\left.y_{i t}=\alpha+\beta \text { (post } \times \text { treat }\right)+\eta_{s t}+\gamma_{c}+\Phi X_{i t}+\varepsilon_{i t},
$$

where $\mathrm{i}$ is an individual taxpayer, $\mathrm{t}$ is a tax year, $\eta_{\mathrm{st}}$ is a set of state by year fixed effects, and $\gamma_{\mathrm{c}}$ are dummies indicating the number of children $(0,1,2,3+)$. Demographic controls, $X_{i t}$, include age, education, race, ethnicity, and divorced status of the mother. To focus on OBRA 93, we only use tax years 1991 through 1998, including two years before and after the legislation has fully phased in (figure 2). The DD estimate is $\beta$, where post is equal to one for any year after 1993. The structure of the OBRA 93 expansion creates two natural comparisons: First, we assign those with children to the treatment group and those without children to the control group. Second, to leverage the larger expansion in OBRA 93 for those with two or more children (figure 2), we also estimate models in which women with two or more children are the treatment group and those with exactly one child are the control group (excluding those without children). We estimate this model for outcomes (y) employment, and indicators equal to one if ATT income is above multiples of the poverty threshold.

The DD estimator naturally works well when there is a single treatment event. However, as described above, there were several EITC expansions over time and across groups. To fully utilize the variation in EITC policy, we replace (post xtreat) with a "simulated" EITC that varies by tax year and number of children. ${ }^{18}$ The simulated EITC is a single variable that

\footnotetext{
${ }^{18}$ This method of summarizing complex policy parameters has been used for other programs including Medicaid (Brown et al 2014, Cutler and Gruber 1996, Currie and Gruber 1996a, Currie and Gruber 1996b, Gruber and Yelowitz 1999) and income taxes (Gruber and Saez 2002, Eissa and Hoynes 2004, Dahl and Lochner 2012, Milligan and Stabile 2011).
} 
summarizes changes in the EITC schedule over time and within group (figures $1 \& 2$ ). We calculate the simulated federal EITC in the following way ${ }^{19}$ : We begin with our sample of single women in tax year 1982, before the first major expansion in 1986 and free of behavior modifications due to the EITC expansions. We then replicate the sample for each tax year in which we would like a simulated EITC. Next, we use the CPI-U to convert the income values in the sample from 1982 dollars into current dollars. Then, we use TAXSIM to calculate the amount of EITC each of these replicated taxpayers would receive if they had existed in the current year. Finally, for each tax year and group (0, 1, and 2 or more children) we take the (sample weighted) average of the EITC value. In this calculation, except for inflation, the sample remains a collection of taxpayers from 1982, but the tax code changes with each replicated year. The result is an average benefit that summarizes changes in policy (and varies by tax year and family size) without including changes in benefits due to family labor supply decisions. Equation (1), modified for the simulated EITC, is

$$
\mathrm{y}_{\mathrm{it}}=\alpha+\beta \overline{\mathrm{SIMEITC}}_{\mathrm{ct}}+\eta_{\mathrm{st}}+\gamma_{\mathrm{c}}+\Phi \mathrm{X}_{\mathrm{it}}+\varepsilon_{\mathrm{it}}
$$

where $\overline{\text { SIMEITC }}_{\mathrm{ct}}$ is the simulated EITC, and captures the average generosity of the credit for family size c in tax year t. Equation (2) also allows us to extend the sample backwards to tax year 1984, taking advantage of variation caused by several expansions and smaller changes in the EITC schedule across earnings, over time and across group.

As with the OBRA 93 difference in difference, this approach (a "parametrized difference in difference") relies on identification at the tax year by family size level. We test the robustness of our main findings by introducing a rich set of controls that vary by year and family size (we

\footnotetext{
${ }^{19}$ To be clear, in this paper we calculate income taxes in two ways. The first uses observed individual taxpayer information to approximate actual tax liability. The second we call "simulated". Our goal with simulated income taxes and transfers is to summarize policy changes across time and groups without including individual taxpayer behavior.
} 
call this our "conservative controls"). ${ }^{20}$ First, we control for generosity of cash welfare policies by using a simulated measure of AFDC and TANF benefits using the same procedure described for the federal EITC, but employing a state-specific welfare calculator (Hoynes and Luttmer 2011). This simulated measure captures changes in benefit parameters across state, year and family size (e.g. and equals 0 for those with no children). We also include an indicator equal to one if a particular state had any welfare waiver in a particular year and allow the coefficient on the waiver to differ depending on the number of children. ${ }^{21}$ To account for other changes in the tax code, we include simulated income taxes before credits (which like the simulated EITC varies by tax year and family size). Finally, local labor market conditions may play an important role; our conservative controls also includes state-level unemployment rates interacted with number of children. This amounts to adding variables $Z_{s t}$ and $Z_{s t} \mathrm{x}$ treat to the model.

The reduced form estimates from equations (1) and (2) are not directly comparable; one is a simple DD and the other parametrizes the changes in the credit over time. To make comparisons across specifications easier, we rescale our reduced-form estimates. We estimate a first stage using equations (1) and (2) but change the outcome $\left(\mathrm{y}_{\text {it }}\right)$ to the federal EITC, calculated using observed individual taxpayer information (including income). Dividing the reduced form from equations (1) and (2) by this first stage (indirect least squares) reinterprets the effect in terms of policy-driven increases in federal EITC dollars. We can then divide the indirect least squares estimate by the dependent mean to get a percent impact. We also calculate an

\footnotetext{
${ }^{20}$ See data appendix for more details regarding the construction of these controls.

${ }^{21}$ We construct these control variables to capture variation at the state-year-family size level to address the potential for unobserved differences across family sizes over time (our identifying variation). When estimating the model comparing single women with children to women without children, we include the main effect for the control and the control interacted with a dummy for having one or more children (the treatment). When estimating the model comparing single women with two or more children to women with one child, we include the main effect for the control and the control interacted with a dummy for having two or more children (the treatment).
} 
"extensive margin elasticity" to compare estimates across specifications and with estimates in the literature (Chetty, Guren, Manoli and Weber 2013). ${ }^{22}$

Finally, we can modify equation (1) to test the validity of our design by interacting the treatment group indicator with year specific indicators instead of a single post-event indicator. In subsequent discussion we call the following equation the "event time model,"

$$
y_{i t}=\alpha+\sum_{j=t^{0}}^{T} \beta_{j}[I(t=j) \times \text { treat }]+\eta_{s t}+\gamma_{c}+\Phi X_{i t}+\varepsilon_{i t}
$$

where $t^{0}$ is the first year in the sample, $T$ is the final tax year in the sample, and $I(t=j)$ is an indicator equal to one if the current year is equal to $\mathrm{j} .{ }^{23} \mathrm{~A}$ coefficient of interest, $\beta_{\mathrm{j}}$, is the difference between the treatment and control groups, in period $\mathrm{j}$ (relative to the omitted year), given the same set of controls used in equation (1). In the figures below we define treatment and control groups in three ways. First, we compare those without children to those with children.

Second, we compare those without children to those with exactly one child separately from those with two children. Finally, we exclude those without children and include only those with two or more children in the treatment group. When we plot the estimates of $\beta_{\mathrm{j}}$ we are specifically looking for trends away from zero in the periods before the treatment took effect. These preperiod differences may indicate unobserved differences in the treatment and control groups that we are not adequately controlling for.

\section{Results}

We begin with examining the basic trends over time for our sample of single women, separately for those with zero, one and two or more children, for 1984 to 2012 . Figure 4 shows

\footnotetext{
${ }^{22}$ See data appendix for more details regarding the calculation of the extensive margin elasticity.

${ }^{23}$ We normalize to drop the coefficient for the year prior to the policy expansion, 1993 for OBRA 93.
} 
annual employment rates and Figure 5 plots the share of single women whose family ATT income is above $100 \%$ of the federal poverty threshold. In the mid-1980s, employment rates and the share above poverty were much lower for women with children compared to those without children (with the largest differences for those with 2 or more children). Beginning in the early 1990s, there is a trend break for those with children and by the early 2000s, the share employed is similar across groups. The share with ATT income above poverty also changes for those with children in the 1990s at approximately the same time as the OBRA 93 EITC expansion. Those with two or more children exhibit a change that is larger than those with only one child (for employment and the share with income above poverty), mirroring the differential EITC benefit expansions of the 1990s.

Next, we turn to the regression results. We begin by presenting results for employment, to replicate and extend the prior results in the literature. Table 2 contains difference-in-difference estimates of the effect of the OBRA 93 EITC expansion on employment (equation 1). The first two columns define the treatment group as single women with one or more children (compared to the control with no children). The second two columns limit the sample to single mothers and compare women with two or more children (the treatment group) to women with one child (the control group). For each model we present results with and without the conservative control set. Relative to single women without children, the share of single women with children who are employed increased by 6.1 percentage points, or 4.7 percentage points with the conservative control set. The indirect least squares estimates are much closer in magnitude: A $\$ 1,000$ policyinduced increase in federal EITC income increases employment by 7.3 and 7.4 percentage points respectively. The implied extensive margin elasticities are 0.36 or 0.37 . Limiting the sample to 
those with children (columns 3 and 4) show similar results with elasticities of 0.45 and 0.32 ,

though although the estimate with the conservative control is no longer statistically significant. ${ }^{24}$

These estimates overall are consistent with the range of estimates in the literature. Chetty, Guren, Manoli and Weber (2013) estimate extensive margin elasticity of 0.30 for Eissa and Liebman (1996) and 0.43 for Meyer and Rosenbaum (2001), the most cited studies on employment. Before moving on to our main results for the distribution of income, we extend our quasi-experimental approach back to 1984 and examine the validity of the design by estimating the event study models.

Tables 3 and 4 contain estimates of equation (2), in which we replace the traditional DD interaction with a simulated measure of the EITC. First, for comparison to the OBRA 93 DD estimates, Table 3 presents the parameterized difference-in-difference estimates for the same period (1991-1998). Here we find percent impacts (per \$1000 in EITC) and elasticities that are very similar to those from the DD specification (but are more precise). For example, when comparing single women with children to those with no children and with the conservative control set, the DD estimate (Table 2, column 2) shows that a policy-induced $\$ 1000$ increase in the EITC leads to an 8.8 percent increase in employment for an extensive margin elasticity of 0.37. The parametrized difference-in-difference (Table 3, column 2) shows an 8.5 percent increase in employment for an elasticity of $0.36 .^{25}$ Table 4 extends the parametrized DD analysis to include EITC expansions enacted with TRA 86 and OBRA 90 by including tax years 1984 through 1998. Overall the results are remarkably stable over time, although the elasticities based on the comparison of women with and without children show somewhat smaller elasticities for

\footnotetext{
${ }^{24}$ Appendix table 2 contains the DD estimates for other levels of education. These estimates, normalized by the first stage, are generally similar to those for our preferred sample of single women with some college education.

25 The simulated EITC is constructed using the 1983 CPS. This may be "too far" from OBRA 93 to accurately reflect the changes the act induced in the income tax code or from welfare reform. Appendix table 3 contains estimates that use the 1993 CPS to construct the simulated EITC, and finds similar results.
} 
the full period compared to the OBRA 93 period. Across all of these results, the conservative control set matters less than the composition of the treatment and control group.

We now turn to the estimates from equation (3), the event time model (estimated using the base model without conservative controls). Figure 6 plots the coefficients and 95 percent confidence intervals for the model where the treatment group is those with children and the omitted year is 1993 (the year prior to the policy expansion). The graph also displays the change in the real average maximum credit for those with children relative to those without children (right axis) to give some guidance as to how the EITC is changing over time and across group. Figure 7 plots a similar graph, where the effect is estimated separately for those who have one child and for those who have two or more children (for each the control is women without children). Figures 6 and 7 combine to show that the differential labor supply increases after 1993 closely follow the pattern of EITC expansions_-women with children increase their employment relative to women without children with larger effects for women with two or more children (who experienced a larger expansion). Further, and importantly, there is little evidence of preevent trends, validating our research design. ${ }^{26}$

Referring back to Figure 2, the EITC schedule for women with one and two or more children had virtually identical schedules prior to the OBRA 93 expansion. This produces a natural check on the validity of our design: When we compare taxpayers with two or more children to those with exactly one child (excluding those without children), we should find no trending differences between treatment and control groups prior to tax year 1994. Figure 8 contains estimates from the event time model, using tax years 1984 through 1998, comparing those with two or more to one child. This facilitates a pre-trend check for almost 10 years. There

\footnotetext{
${ }^{26}$ When comparing women with children to women without children (Figure 6-7), we include only two years of pre data given that there was another expansion due to OBRA 90.
} 
is some noise in the estimates for periods prior to tax year 1994, but the difference in the share employed between the two groups clearly diverges beginning after tax year 1993, and increases through the years of the EITC expansion. ${ }^{27}$

We now move to our main results exploring the effect of the EITC on the distribution of income. We start by using the variation induced by OBRA 93, following equation (1), where the outcome variable $\left(\mathrm{y}_{\mathrm{it}}\right)$ is a dummy equal to one if a woman's ATT income is above a given multiple of the federal poverty threshold. We begin by examining estimates for income above 100 percent of poverty; below we extend this to consider effects more comprehensively on the distribution of income (from 25 percent of poverty to 500 percent of poverty).

Table 5 presents the estimates for the OBRA 93 difference-in-difference model. Relative to single women without children, single women with children experienced an increase in the share with ATT income above the poverty threshold of 7.9 percentage points with OBRA 93 (column 1). Adding the conservative controls (column 2) leads to similar effects. We rescale these reduced form estimates in the same way as those above; column 1 shows that a $\$ 1000$ policy-induced increase in the EITC leads to a 9.4 percentage point increase in the propensity to have ATT income above poverty. This implies an elasticity of 0.64 . If we utilize just the expansion across 1 versus 2 or more children (column 3 and 4), we find that a $\$ 1000$ policyinduced increase in the EITC leads to a 4.7 to 5.4 percentage point increase in the propensity to have ATT income above poverty. These estimates capture the full behavioral effect of the EITC including the direct effect of the credit as well as the indirect effect though changes to earnings and other income. Note that the elasticities for ATT poverty are larger than those of employment,

\footnotetext{
${ }^{27}$ The increase in the share employed across family size has endured to the present. Appendix figures 2-4 extend estimates from the event model up to the last year of available data (tax year 2013). The pattern of change in employment across family size has endured through the 2001 and 2008 labor market downturns.
} 
reflecting the density of single taxpayers with children whose income puts them around $100 \%$ of the federal poverty threshold (table 1).

We explore further the effects of OBRA 93, and test the validity of our design, by estimating the event model (equation 3) where the dependent variable is equal to one if ATT income exceeds $100 \%$ of the poverty threshold. Figure 9 examines OBRA 93 comparing single women with children to single women without children, over 1991-1998. As with the earlier event study graphs, on the right axis we plot the increase the maximum credit (for treatment relative to control, relative to the differences in the omitted year 1993). The graph shows a sharp increase in the propensity to have ATT income above poverty beginning in 1994 . The increase follows closely the expansions in the EITC. Additionally, and importantly, the share above poverty prior to OBRA 93 looks to be quite flat between the treatment and control, confirming the validity of the quasi-experimental design.

As with our analysis of employment, if we limit the sample to women with children and compare those with two or more children to those with one child, we can analyze the effects of OBRA 93 with a much longer (10 year) pre-period. The estimates of that event study, again applied to the propensity to have ATT income above 100 percent poverty, is plotted in Figure 10. Using this 1984-1998 time frame, the estimates provide striking evidence that the share with ATT income above poverty increases sharply with the expansion of the EITC. Additionally, it is reassuring that there is no evidence of any differential trending in the treatment versus control group over this long pre-trend period.

The differential in the propensity to have ATT income above $100 \%$ of the federal poverty threshold has endured over time. Appendix figures 5-7 estimate the event model for all available tax years (1984-2013) using three different designs ( 0 vs $1+$ children, 0 vs 1 vs $2+$ children, and 
1 vs $2+$ children). The results show that the propensity to have ATT income above poverty follows closely the changes in the EITC over time. Additionally there has not been deterioration in the effects with the weak labor market of the 2000 s.

We extend these results to examine effects comprehensively across the distribution of income. To do so, we estimate a series of difference-in-difference models for OBRA 93 where the dependent variable is an indicator equal to one if after-tax and transfer-income is above a multiple of the poverty threshold. In particular, we estimate models as presented in Table 5 (for the share above 100 percent of the poverty threshold); we vary the threshold in 25 percentile bins from ATT income above 25 percent of poverty to ATT income above 500 percent of poverty. Figure 11 contains estimates in which we compare families with children to those without children. In the figure, each estimate (and 95 percent confidence interval) comes from a separate regression; we graph them together to illustrate the effects of the credit on the distribution of income. For example, consider the point for ATT income above 100 percent poverty plotted in Figure 11. The estimate, 0.079 , is the same as that presented previously in Table 5-the interpretation is that OBRA 93 increased the propensity for single women with children to have ATT income above the poverty threshold by 7.9 percentage points. ${ }^{28} \mathrm{We}$ overlay on the figure the change in the difference-in-difference in the EITC credit at each of these income-to-poverty bins. Figure 12 presents estimates for those with two or more children compared to those with only one child.

These figures suggest several important findings. First, the EITC has little effect on the very lowest income groups: the EITC has an estimated zero effect on the share above poverty for those with income below $50 \%$ of the poverty threshold. This may reflect that the very lowest

\footnotetext{
${ }^{28}$ In each case we are plotting the coefficient on post $\mathrm{x}$ treat (as in equation 1); the estimates are not scaled as we want to illustrate the reduced form "program evaluation" of the credit, rather than the effect per dollar of treatment.
} 
income groups have little attachment to the labor market. Second, the effects of the EITC are large and statistically significant between $75 \%$ and $150 \%$ of the poverty line. The largest effects occur around $100 \%$ of the federal poverty threshold. The estimated effects decay and fall to zero by $250 \%$ poverty. These patterns of results are very consistent with expectations, based on the shape and location of the EITC schedule (relative to poverty thresholds), as illustrated by the overlay of the EITC policy changes on the figure. This concordance between our estimated impacts (capturing the direct and indirect effects of the credit) provides strong evidence that we are indeed capturing the causal effects of the EITC on the distribution of income. Further, and substantively, these are large effects and illustrate the potential for this important safety net policy to affect lower tail income inequality.

We also extend this analysis using the parametrized difference-in-difference model and the simulated EITC, utilizing the full period of policy expansions covering 1984-1998 (TRA86, OBRA90 and OBRA93). Table 6 contains the results where the dependent variable equals one if ATT income is above $100 \%$ of the federal poverty threshold. The results show that a $\$ 1000$ increase in policy-induced EITC income leads to a 13 percent (for children versus no children) to 13.9 percent (for 2 children versus 1 child) increase in the propensity to have ATT income above poverty. This implies elasticities of 0.57 to 0.68 . (The results are little changed by adding the conservative controls.) Looking back at Table 5, these estimates are very similar to the difference-in-difference estimates for OBRA 93.

Finally, we use the parametric difference-in-difference model to estimate a series of coefficients where we vary the threshold in 25 percentile bins (from ATT income above 25 percent of poverty to ATT income above 500 percent of poverty). Figure 13 presents estimates for single women with 0 versus $1+$ children (filled circles) and single women with 1 versus 
$2+$ children (open circles). As above, we combine the models and plot together the estimates (and 95 percent confidence intervals) across bins of income to poverty. These results confirm our earlier findings based on the OBRA93 expansion. We find no effect at the lowest levels of income (25\% and $50 \%$ poverty), large effects centered on $100 \%$ of poverty, and decaying effects going to zero by $250 \%$ of poverty. The parametrized difference-in-difference model is more precisely estimated and the results remain significant through 225\% poverty. Appendix Figure 8 shows that the estimates are very similar with and without the conservative controls.

\section{The Direct and Indirect Effects of the EITC on the Distribution of Income}

We began, in the introduction, by pointing out that the prior evidence on the effects of the EITC on poverty took a static approach, capturing the direct effects of the credit but omitting the dynamic or indirect effects operating through the incentivized increases in earnings. We demonstrated the importance of the extensive margin effect (with our estimates for employment) and went on to estimate the effect of the EITC on ATT income (relative to poverty) thereby capturing the direct and indirect effects. Here, we can apply these estimates to simulate the aggregate number of individuals and children who are raised above poverty from the EITC.

This analysis starts with the CPS including single women with children ages 24-48 with some college education or less, for calendar year $2012 .{ }^{29}$ For these simulations, we consider the entire family including the mother and each of her children and use the CPS weights to generate aggregate counts. First, as a reference, we calculate the total number of children (Figure 14) and individuals (Figure 15) that the EITC lifts out of poverty using the Supplemental Poverty Measure or SPM (labeled "Static SPM" in the figures). Second, we use our ATT income

\footnotetext{
${ }^{29}$ The 2012 data comes from the 2013 CPS survey year. Our last year of data corresponds to the 2014 CPS (with 2013 calendar year data) but, at the time of this writing, the SPM variables have yet to be added to the IPUMS-CPS. See data appendix for more details on the calculations in this section.
} 
measure along with the official poverty thresholds to provide a similar static calculation (labeled "Static ATT poverty" in the figures). Both of these are calculated by zeroing out the EITC credit, recalculating the poverty measure and, using the CPS weights, aggregating up the number of children (or total individuals) who are raised above poverty assuming no other change in behavior (hence the calculation is static). Figure 14 shows that, based on the Static SPM, the EITC lifts 1 million children out of poverty. Our static ATT poverty shows a similar result, through a bit larger at 1.2 million. ${ }^{30}$ You will notice that our calculation, that the EITC raises 1 million children above poverty, is below the 4.7 million estimated from the SPM (reported above, see Short 2013). This is because our calculations derive from our sample (single mothers 24-48 with some college or less, along with their children) and despite their relatively high poverty rate, our sample accounts for only about $17.5 \%$ of individuals who are poor (based on official poverty). ${ }^{31}$ The static calculations, though, are only used here as a reference to compare to the calculations that incorporate the indirect or behavioral effects.

Also plotted in Figures 14 and 15 are aggregate counts of "ATT poverty with behavior," simulated based on our estimates from Section 6. Using estimates from our parameterized difference-in-difference model (estimated including data from 1984-2013), we simulate the number of persons (and children) lifted above the poverty threshold by predicting the model at the observed simulated EITC (for 2012) and comparing to the prediction with the simulated EITC zeroed out (for details see the data appendix).

\footnotetext{
${ }^{30}$ Our ATT poverty measure differs from the SPM in two central ways. First, the SPM includes a more comprehensive resource measure deducting out of pocket medical expenses and work expenses and including the cash value of medical expenses. Second, the SPM is based on a new poverty threshold that builds in geographic variation and expenses on housing, utilities and food. We developed and use the ATT income and poverty (instead of the SPM) because we can measure it consistently back to 1980. This cannot be done easily with the SPM. ${ }^{31}$ Additionally, the number reported in Short $(2013,2014)$ includes the effects of the EITC and the Child Tax Credit.
} 
The results, presented in Figures 14 and 15, are dramatic. The number of children that the 2012 EITC raised above poverty increases from 1.2 million to 2.3 million when we use our estimates to predict the effects of the EITC. Similarly, the total number of individuals lifted above poverty by the 2012 EITC rises from 1.8 million to 3.4 million. Ignoring the indirect effects of the EITC, and the incentivized increase in earnings, underestimates the number of persons raised out of poverty by about 50 percent.

We extend this analysis by making similar calculations at other points in the income-topoverty distribution: $50 \%, 150 \%, 200 \%, 250 \%$ and $300 \%$ of the federal poverty threshold. The results show significant underestimates of the effects of the EITC on the propensity to raise incomes above $150 \%$ and $200 \%$ of poverty. Overall, these results suggest that the already sizable contribution to increasing income and reducing poverty attributed to the EITC is significantly understated when all of the programs incentives are taken into account.

\section{Conclusion}

In this paper we comprehensively examine the effects of the EITC on employment and the distribution of income. We use a quasi-experimental research design that leverages the variation in the generosity of the EITC across family sizes and over time. Our analysis of employment largely updates the literature, and presents event study graphs to test and validate the well-used research design. More importantly, we provide the first comprehensive estimates of the federal EITC on the distribution of family income relative to poverty. Our approach quantifies the effects on pre-tax income as well as the direct effect of the credit. We explore the effects of the EITC on the distribution of income, capturing where the program leads to increases income and how after-tax and transfer-income poverty is affected. 
Our results show that a $\$ 1000$ policy-induced increase in the EITC lead to a 7.3

percentage point increase in employment and a 9.4 percentage point reduction in the share of families with after-tax and transfer income below $100 \%$ poverty. These results are robust to a rich set of controls including income from other safety net programs (such as AFDC/TANF and SNAP that decrease with the EITC expansion), controls for welfare reform, and labor market conditions; all allowed to vary by family size (our identifying variation). They are also robust to using tax-policy driven reforms across single women with and without children, as well as single women with one versus two or more children and whether we use the sharp changes in the 1993 EITC expansion or policy changes back to the 1986 Tax Reform Act.

Furthermore, we also provide estimates on how the EITC effects the income distribution more broadly. We find little effect on incomes below 50\% poverty. The effects of the EITC are large and statistically significant between $75 \%$ and $150 \%$ of poverty (peaking at $100 \%$ poverty), and decay down to zero at $250 \%$ of poverty. The pattern of effects across the income distribution reflects where the credit is providing the largest transfers. Importantly, by capturing the indirect effects of the credit on earnings, our results show that static calculations of the anti-poverty effects of the EITC (such as those released based on the Supplemental Poverty Measure) may be underestimated by as much as 50 percent.

Future work could extend this analysis to other groups. The increase in after tax incomes from the EITC may be the largest for this group - single women with children - given their welldocumented large extensive margin labor supply response to this policy. Married couples, though representing less than a quarter of EITC expenditures, may exhibit smaller increases in income.

Given that the goal of the EITC is to increase family income while encouraging work, these estimates provide important evidence on the efficacy of this central element of the U.S 
safety net not only to encourage work, but to potentially reduce inequality, raise family income, and move families out of poverty. 


\section{References}

Autor, D., A. Manning and C. Smith. 2010. "The Contribution of the Minimum Wage to U.S. Wage Inequality over Three Decades: A Reassessment.” NBER Working Papers 16533

Autor, David (2014). "Skills, education, and the rise of earnings inequality among the 'other 99 percent", Science.

Baker, Kevin. 2008. "Do Cash Transfer Programs Improve Infant Health: Evidence from the 1993 Expansion of the Earned Income Tax Credit," working paper Notre Dame.

Baughman, Reagan, and Stacy Dickert-Conlin (2009). "The Earned Income Tax Credit and Fertility.” Journal of Population Economics, 22 (3): 537-563.

Bollinger, Christopher, Luis Gonzalez, and James P. Ziliak (2009). "Welfare Reform and the Level and Composition of Income." In Welfare Reform and its Long-Term Consequences for America's Poor. Ed. James P. Ziliak, 59-103. Cambridge, UK: Cambridge University Press.

Bitler, Marianne and Hilary Hoynes. (2010). "The State of the Safety Net in the Post-Welfare Reform Era”, Brookings Papers on Economic Activity: 71-127.

Bitler, Marianne and Hilary W. Hoynes (2014). "The More Things Change, the More They Stay the Same: The Safety Net, Living Arrangements, and Poverty in the Great Recession," Forthcoming, Journal of Labor Economics.

Bitler, Marianne, Hilary Hoynes and Elira Kuka (2014). "Do In-Work Tax Credits Serve as a Safety Net?", NBER WP 19785.

Brown, David, Amanda Kowalski and Ithai Lurie (2014). Medicaid as an Investment in Children: What is the Long-Term Impact on Tax Receipts? Working Paper 20835, National Bureau of Economic Research.

Burkhauser, Richard and Sabia, J. 2007. "The Effectiveness of Minimum Wage Increases in Reducing Poverty: Past, Present, and Future." Contemporary Economic Policy, 25(2): 262-281.

Census (2014). "Poverty Thresholds." http://www.census.gov/hhes/www/poverty/data/threshld/index.html.

Card, David and Alan Krueger. 1995. Myth and Measurement: the New Economics of the Minimum Wage. Princeton University Press: Princeton, NJ.

Chetty, Raj, Emmanuel Saez, and Jonah Rockoff. (2011). New evidence on the longterm impacts of tax credits. Washington, D.C.: U.S. Internal Revenue Service, November.

Chetty, Raj, John Friedman and Emmanuel Saez (2013). "Using Differences in Knowledge Across Neighborhoods to Uncover the Impacts of the EITC on Earnings." American Economic Review, 103(7): 2683-2721.

Chetty, Raj and Emmanuel Saez (2013). 2013. "Teaching the Tax Code: Earnings Responses to an Experiment with EITC Recipients." American Economic Journal: Applied Economics, 5(1): 1-31. 
Chetty, Raj, Adam Guren, Day Manoli and Andrea Weber (2013). "Does Indivisible Labor Explain the Difference between Micro and Macro Elasticities? A Meta-Analysis of Extensive Margin Elasticities," in NBER Macroeconomics Annual 2012, vol. 27: 1-56.

Citro, Constance and Robert Michael, eds. (1995). "Measuring Poverty: A New Approach." Washington D.C.: National Academy Press.

Crouse, Gil (1999). "State Implementation of Major Changes to Welfare Policies, 1992-1998," US Department of Health and Human Services, Assistant Secretary for Planning and Evaluation. http://aspe.hhs.gov/hsp/waiver-policies99/policy_cea.htm.

Currie, Janet, and Jonathan Gruber (1996a). "Health Insurance Eligibility, Utilization of Medical Care, and Child Health.” The Quarterly Journal of Economics, 111 (2): 431-66.

--- (1996b). "Saving Babies: The Efficacy and Cost of Recent Changes in the Medicaid Eligibility of Pregnant Women.” Journal of Political Economy, 104 (6): 1263-96.

Cutler, David M., and Jonathan Gruber (1996). "Does Public Insurance Crowd out Private Insurance." The Quarterly Journal of Economics, 111 (2): 391-430.

Dahl, Gordon B., and Lance Lochner (2012). "The Impact of Family Income on Child Achievement: Evidence from the Earned Income Tax Credit." American Economic Review, 102 (5): 1927-1956.

Department of Health and Human Services, Office of the Assistant Secretary for Planning and Evaluation (1997). "Setting the Baseline: A Report on State Welfare Waivers," http://aspe.hhs.gov/hsp/isp/waiver2/title.htm.

Dickert-Conlin, Stacy, and Amitabh Chandra (1999). "Taxes and the Timing of Births." Journal of Political Economy, 107 (1): 161-177.

Dube, Arindrajit (2013). "Minimum Wages and the Distribution of Family Incomes," mimeo.

Economic Report of the President (2015).

Eissa, Nada, and Hilary W. Hoynes (2004). "Taxes and the Labor Market Participation of Married Couples: The Earned Income Tax Credit.” Journal of Public Economics, 88 (910): 1931-1958.

--- (2006). "Behavioral Responses to Taxes: Lessons from the EITC and Labor Supply," in NBER Book Series Tax Policy and the Economy: Volume 20. Edited by James Poterba, p. 74-110. Cambridge, MA: The MIT Press.

Eissa, Nada, and Jeffrey B. Liebman (1996). "Labor Supply Response to the Earned Income Tax Credit.” The Quarterly Journal of Economics, 111 (2): 605-637.

Evans, William N., and Craig L. Garthwaite. 2014. "Giving Mom a Break: The Impact of Higher EITC Payments on Maternal Health.” American Economic Journal: Economic Policy, 6(2): 258-90.

Frandsen, Brigham. 2012. "Why Unions Still Matter: The Effects of Unionization on the Distribution of Employee Earnings," mimeo.

Gelber, Alexander, and Joshua W. Mitchell (2012). "Taxes and Time Allocation: Evidence from Single Women and Men.” Review of Economic Studies, 79: 863-897. 
Gunderson, Craig and James Ziliak. 2004. "Poverty and Macroeconomic Performance Across Space, Race, and Family Structure.” Demography 41(1): 61-86.

Grogger, Jeffrey (2003). "The Effects of Time Limits, the EITC, and Other Policy Changes on Welfare Use, Work and Income Among Female-Headed Families." The Review of Economics and Statistics, 85(2): 394-408.

Gruber, Jonathan and Emmanuel Saez (2002). "The Elasticity of Taxable Income: Evidence and Implications." Journal of Public Economics, 84: 1-32.

Gruber, Jonathan, and Aaron Yelowitz (1999). "Public Health Insurance and Private Savings." Journal of Political Economy, 107 (6): 1249-1274.

Havnes, Tarjei and Magne Mogstad (2015). "Is Universal Child Care Leveling the Playing Field?" Forthcoming in Journal of Public Economics.

Hotz, V. Joseph and John Karl Scholz (2003). "The Earned Income Tax Credit," in MeansTested Transfer Programs in the United States. Edited by Robert Moffitt, p. 141-197. Chicago, IL: The University of Chicago Press.

Hoynes, Hilary W., Erzo F.P. Luttmer (2011). “The Insurance Value of State Tax and Transfer Programs," Journal of Public Economics 95(11-12): 1466-1484.

Hoynes, Hilary W., Doug L. Miller, David Simon (2015). "Income, the Earned Income Tax Credit and Infant Health," American Economic Journal: Economic Policy, 7(1): 172-211.

Internal Revenue Service (2013). “1040 (2013)," http://www.irs.gov/pub/irs-pdf/i1040gi.pdf.

Internal Review Service (2014). “Individual Income Tax Returns 2012”, Publication 1304, August 2014.

Internal Revenue Service (2014). "States and Local Governments with Earned Income Tax Credits," August 2014. http://www.irs.gov/Individuals/States-and-Local-Governmentswith-Earned-Income-Tax-Credit

Liebman, Jeffrey B. (1998). "The Impact of the Earned Income Tax Credit on Incentives and Income Distribution," in NBER Book Series Tax Policy and the Economy: Volume 12. Edited by James Poterba, p. 83-120. Cambridge, MA: The MIT Press.

Manoli, Day, and Nick Turner. 2014. Cash on hand and college enrollment. Evidence from population tax data and policy nonlinearities. NBER Working Paper no. 19836. Cambridge, Mass.: National Bureau of Economic Research, January.

Meyer, Bruce D. (2010). "The Effects of the Earned Income Tax Credit and Recent Reforms," Tax Policy and the Economy, Edited by Jeffery R. Brown, Volume 24, p. 153-180. Cambridge, MA: The MIT Press.

Meyer, Bruce D. and Dan T. Rosenbaum (2000). "Making Single Mothers Work: Recent Tax and Welfare Policy and its Effects,” National Tax Journal 53(4, part 2): 1027-1062.

--- (2001). "Welfare, the Earned Income Tax Credit, and the Labor Supply of Single Mothers," Quarterly Journal of Economics 116(3): 1063-1114.

Michelmore, Katherine. 2013. The effect of income on educational attainment: Evidence from state earned income tax credit expansions, mimeo. 
Milligan , Kevin and Mark Stabile (2011). Do child tax benefits affect the well-being of children? Evidence from canadian child benefit expansions. American Economic Journal: Economic Policy, 3 (3), 175-205.

Mishel, Kawrence, Josh Bivens, Elise Gould and Heidi Shierholz (2012). The State of Working America, $12^{\text {th }}$ Edition, Employment Policy Institute.

Moffitt, Robert (2003). “The Temporary Assistance for Needy Families Program” in Moffitt, ed. Means Tested Transfer Programs, University of Chicago Press.

Neumark, David, M. Schweitzer and William Wascher. 2005. “The Effects of Minimum Wages on the Distribution of Family Incomes - A Nonparametric Analysis." Journal of Human Resources 40(4):867-894.

Neumark, David and William Wascher. 2001. "Using the EITC to Help Poor Families: New Evidence and a Comparison with the Minimum Wage," National Tax Journal, 54(2):281317.

Neumark, David and William Wascher. 2008. Minimum Wages. The MIT Press.

Neumark, D. and Wascher, W. 2011. "Does a Higher Minimum Wage Enhance the Effectiveness of the Earned Income Tax Credit?" Industrial and Labor Relations Review 64(4):712746.

Nichols, Austin and Jesse Rothstein (2015). “The Earned Income Tax Credit,” working paper.

Piketty, Thomas and Emmanuel Saez (2003). "Income Inequality in the United States, 19131998," Quarterly Journal of Economics, 118(1), 2003, 1-39.

Rothstein, Jesse (2010). "Is the EITC as Good as the NIT? Conditional Cash Transfers and Tax Incidence.” American Economic Journal: Economic Policy, 2 (1): 177-208.

Saez, Emmanuel (2010). "Do Taxpayers Bunch at Kink Points?” AEJ Policy, August 2010.

Short, Kathleen. (2013). “The Research Supplemental Poverty Measure: 2012.” Current Population Reports P60-247. U.S. Census Bureau.

Short, Kathleen. (2014). “The Research Supplemental Poverty Measure: 2013.” Current Population Reports P60-251. U.S. Census Bureau.

Strully, Kate W., David H. Rehkopf, and Ziming Xuan. 2010. "Effects of Prenatal Poverty on Infant Health: State Earned Income Tax Credits and Birth Weight." American Sociological Review 75 (4):534-62.

Tax Policy Center (2014). "Historical EITC Parameters,” January 23, 2014, http://www.taxpolicycenter.org/taxfacts/displayafact.cfm?Docid=36.

Ziliak, James (2015). “Temporary Assistance for Needy Families”, NBER Working Paper 21038. 
Figure 1: Federal EITC Schedule for Taxpayers Filing Single in Tax Year 2013 by Number of Qualifying Children

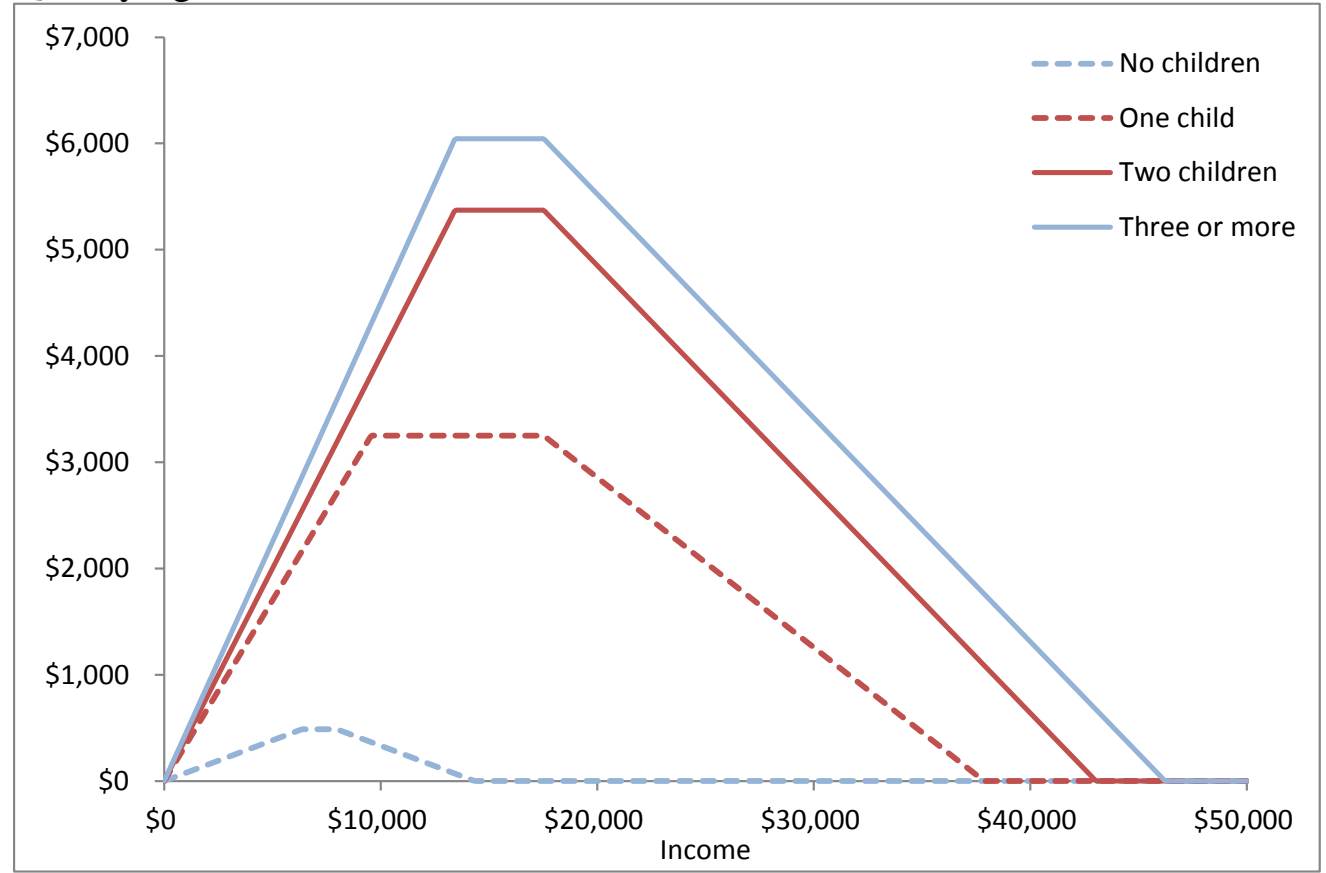

Notes: Tax Policy Center (2014), 2013\$.

Figure 2: Federal Maximum EITC by Tax Year and Number of Qualifying Children

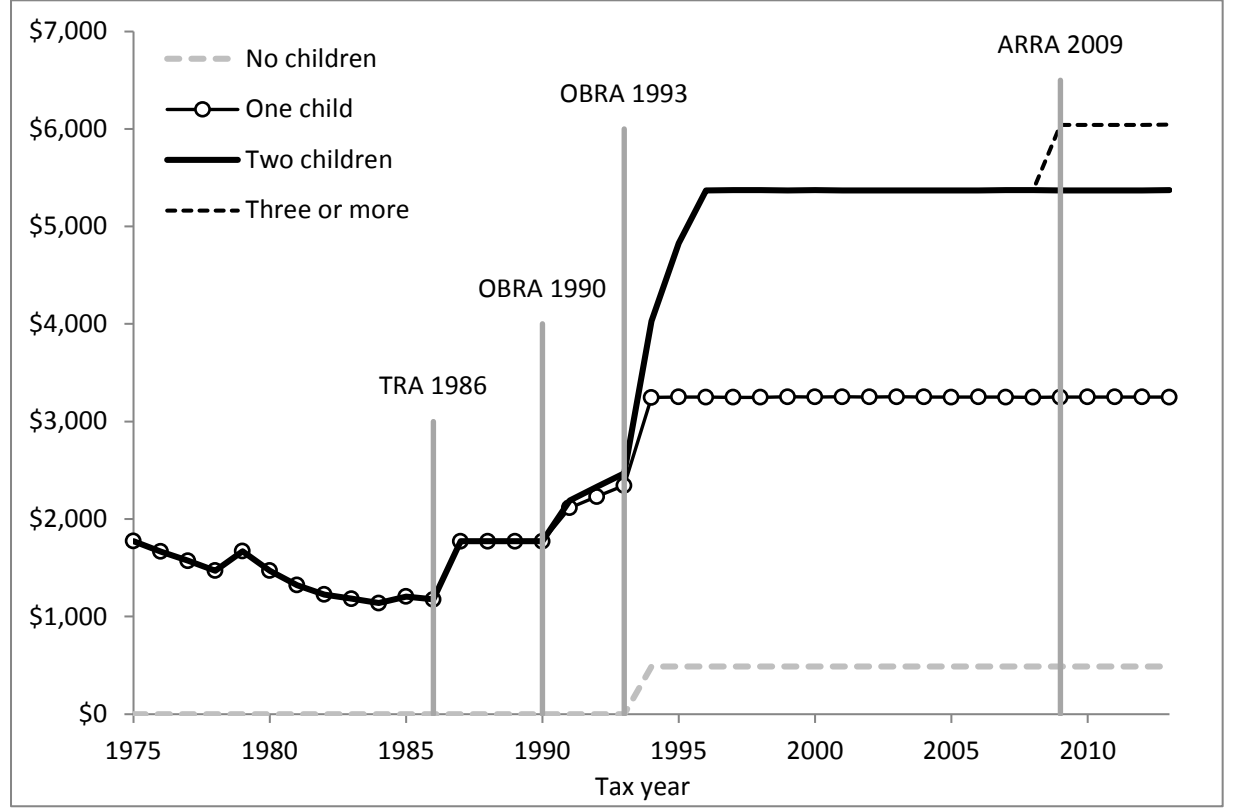

Notes: Tax Policy Center (2014), 2013\$. 
Figure 3: Per Capita Expenditures on Cash and Near Cash Transfer Programs for Families $(2012 \$)$

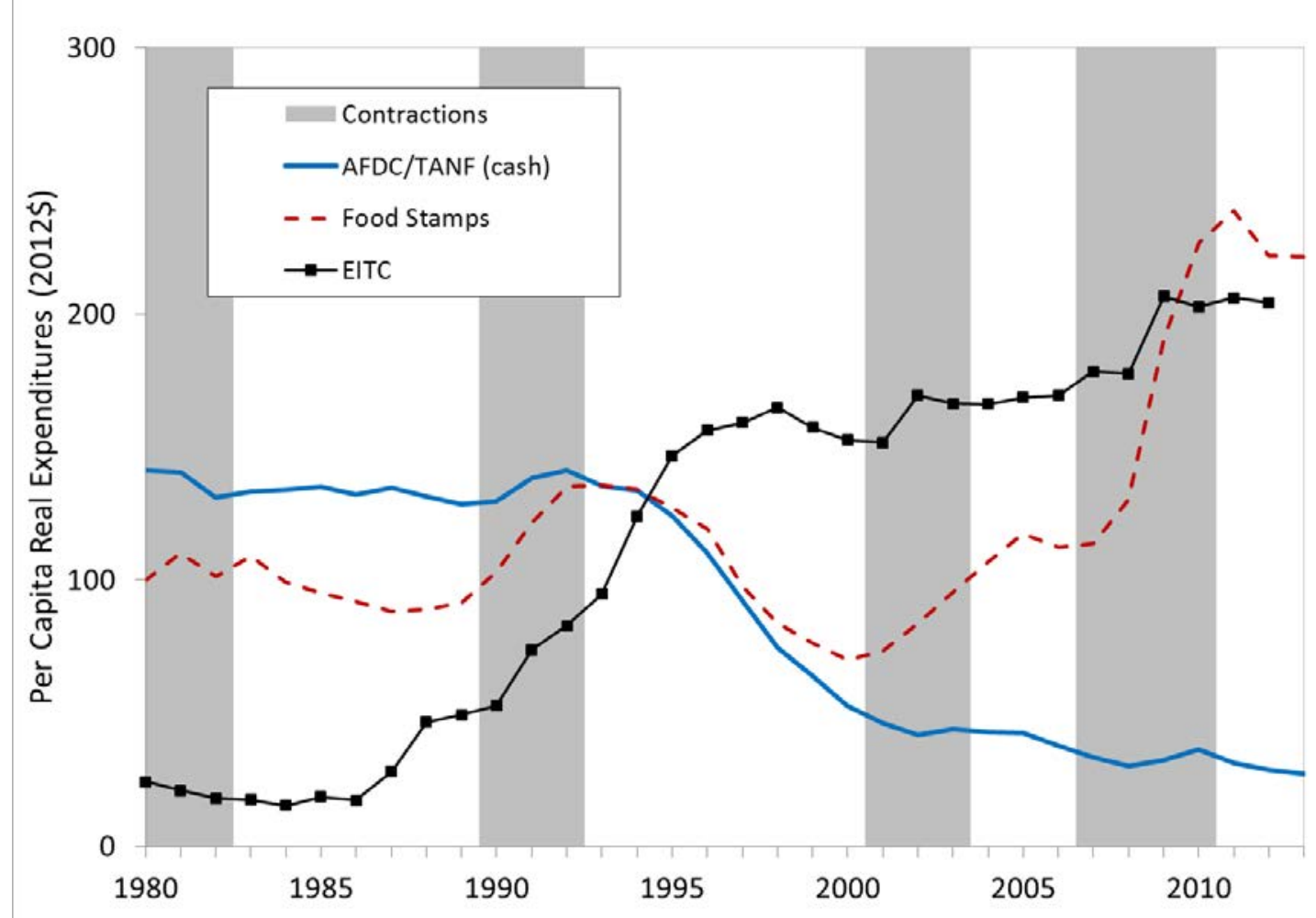

Notes: Bitler and Hoynes (2010), updated to include data through 2013 (or 2012 for the EITC).

Figure 4: Share Employed by Presence and Number of Children

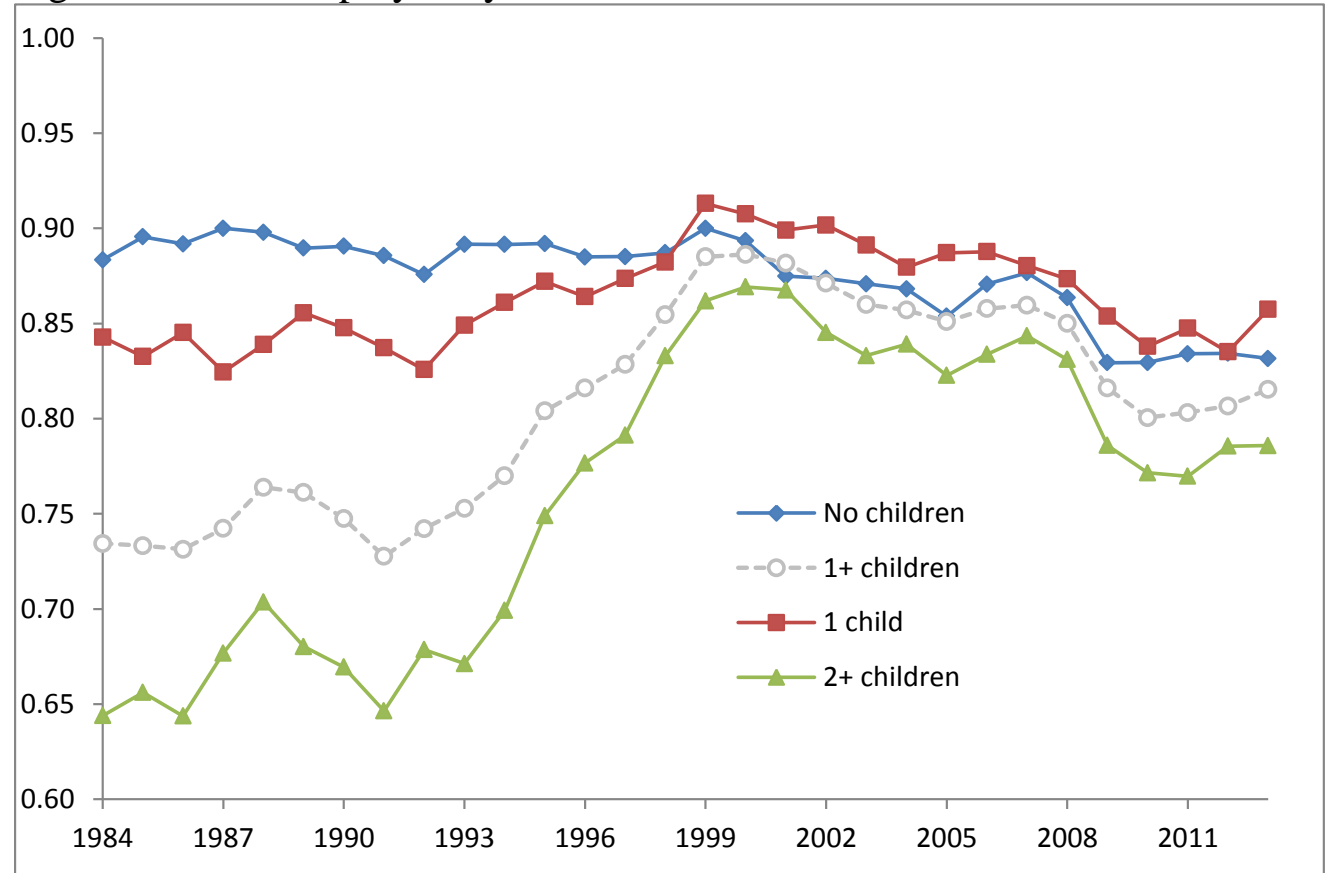

Notes: 1985-2014 CPS, single women, 24-48 years old, with some college education or less. 
Figure 5: Share with ATT Income Above 100\% of Federal Poverty Threshold by Presence and Number of Children

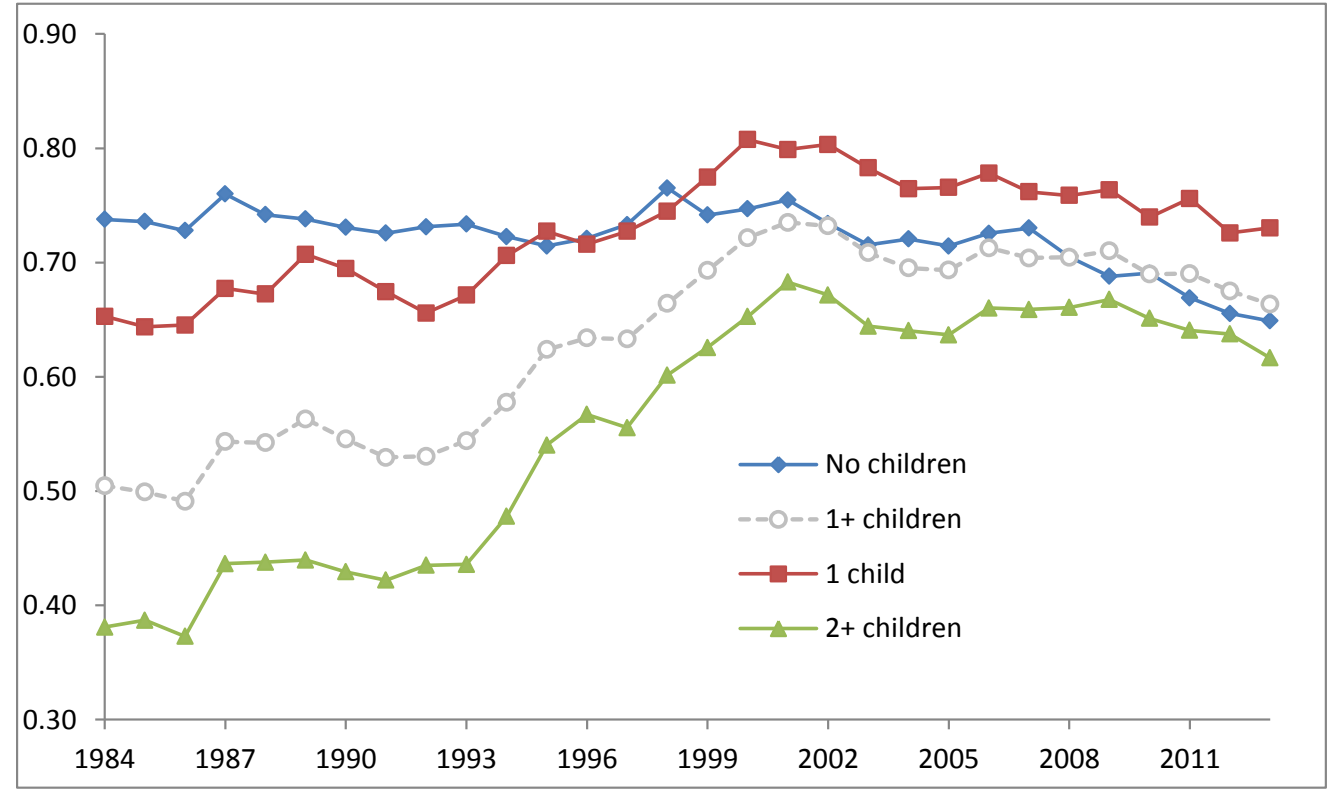

Notes: 1985-2014 CPS, single women, 24-48 years old, with some college education or less. Figure plots share of taxpayers with after-tax and transfer income above $100 \%$ of the federal poverty threshold.

Figure 6: Event Time Model Estimates of OBRA 93 on Employment, 0 vs. 1+ Children

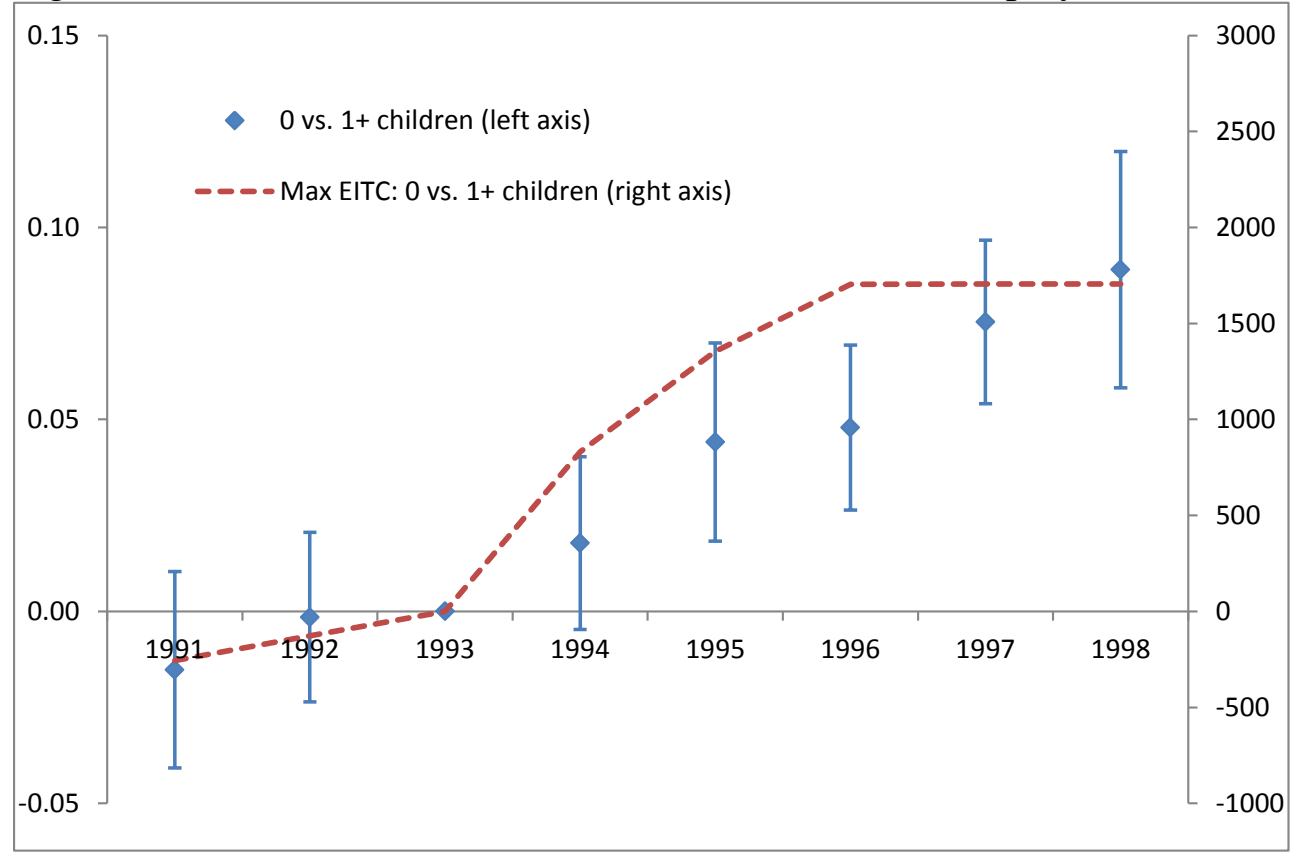

Notes: The sample includes single women, ages 24 through 48 with some college education or less from the 1992 through 1999 Current Population Survey (March). See equation (3) in text and data appendix for details. $95 \%$ confidence intervals clustered on state. 
Figure 7: Event Time Model Estimates of OBRA 93 on Employment by Family Size

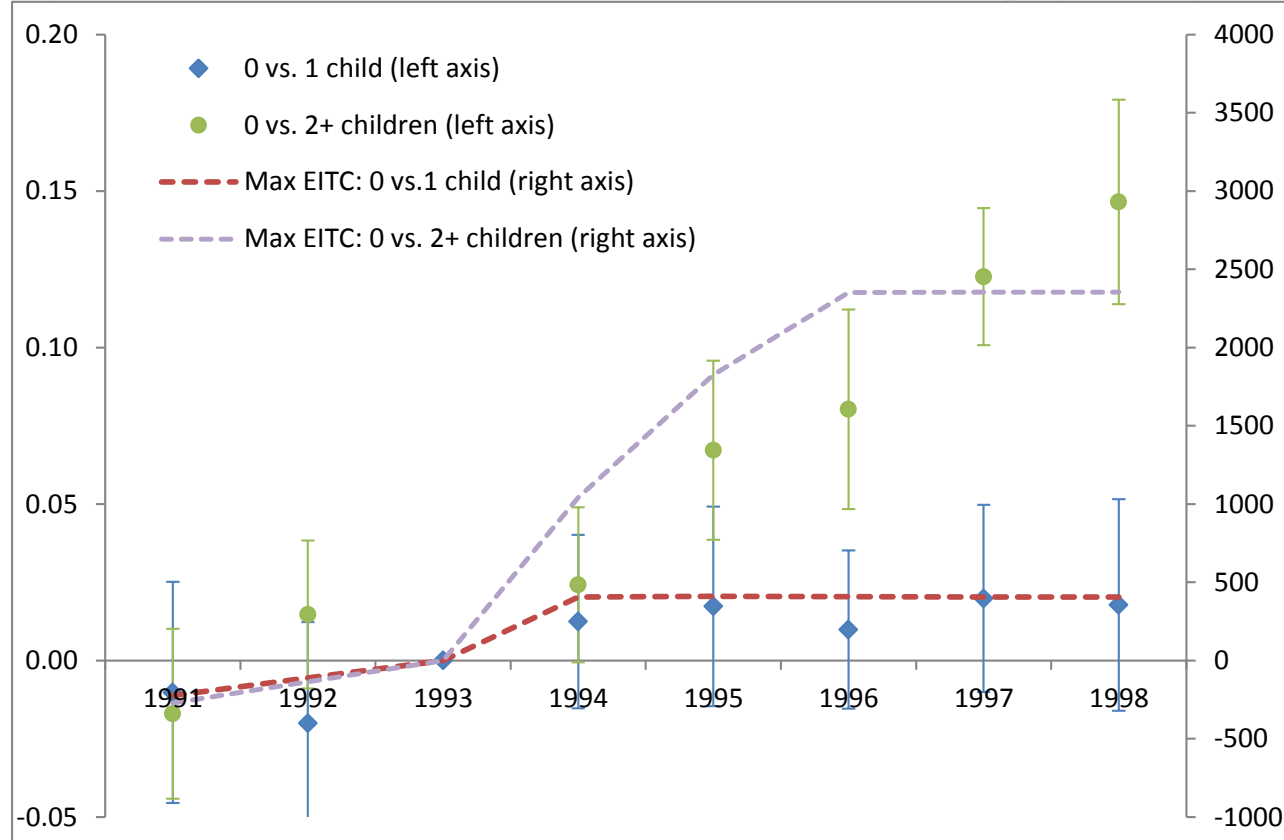

Notes: The sample includes single women, ages 24 through 48 with some college education or less from the 1992 through 1999 Current Population Survey (March). See equation (3) in text and data appendix for details. 95\% confidence intervals clustered on state.

Figure 8: Event Model Estimates of OBRA 93 on Employment, 1 vs 2+ Children

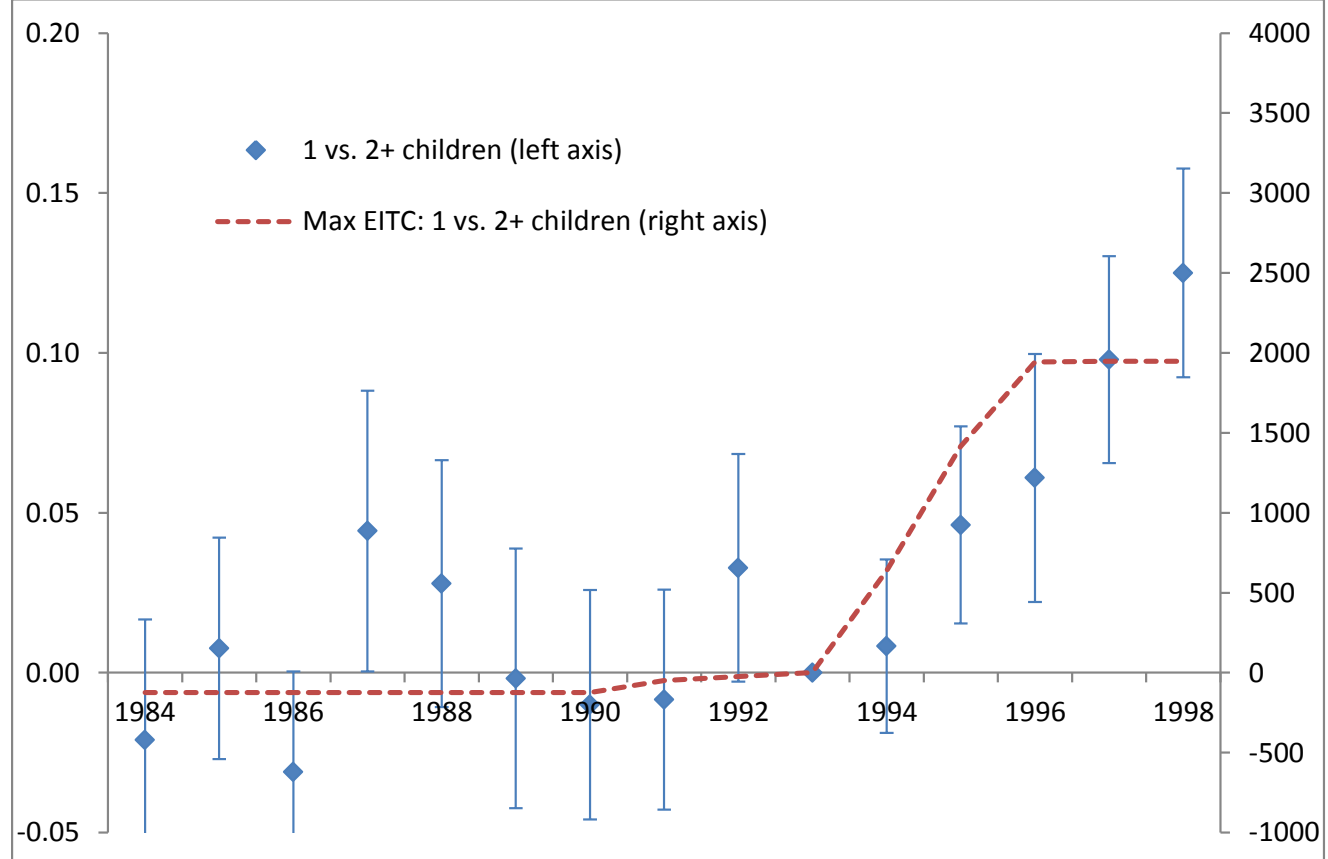

Notes: The sample includes single women with children, ages 24 through 48 with some college education or less from the 1985 through 1999 Current Population Survey (March). See equation (3) in text and data appendix for details. 95\% confidence intervals clustered on state. 
Figure 9: Event Time Model Estimates of OBRA 93 on ATT Income Above 100\% of the Poverty Threshold, 0 vs. 1+ Children

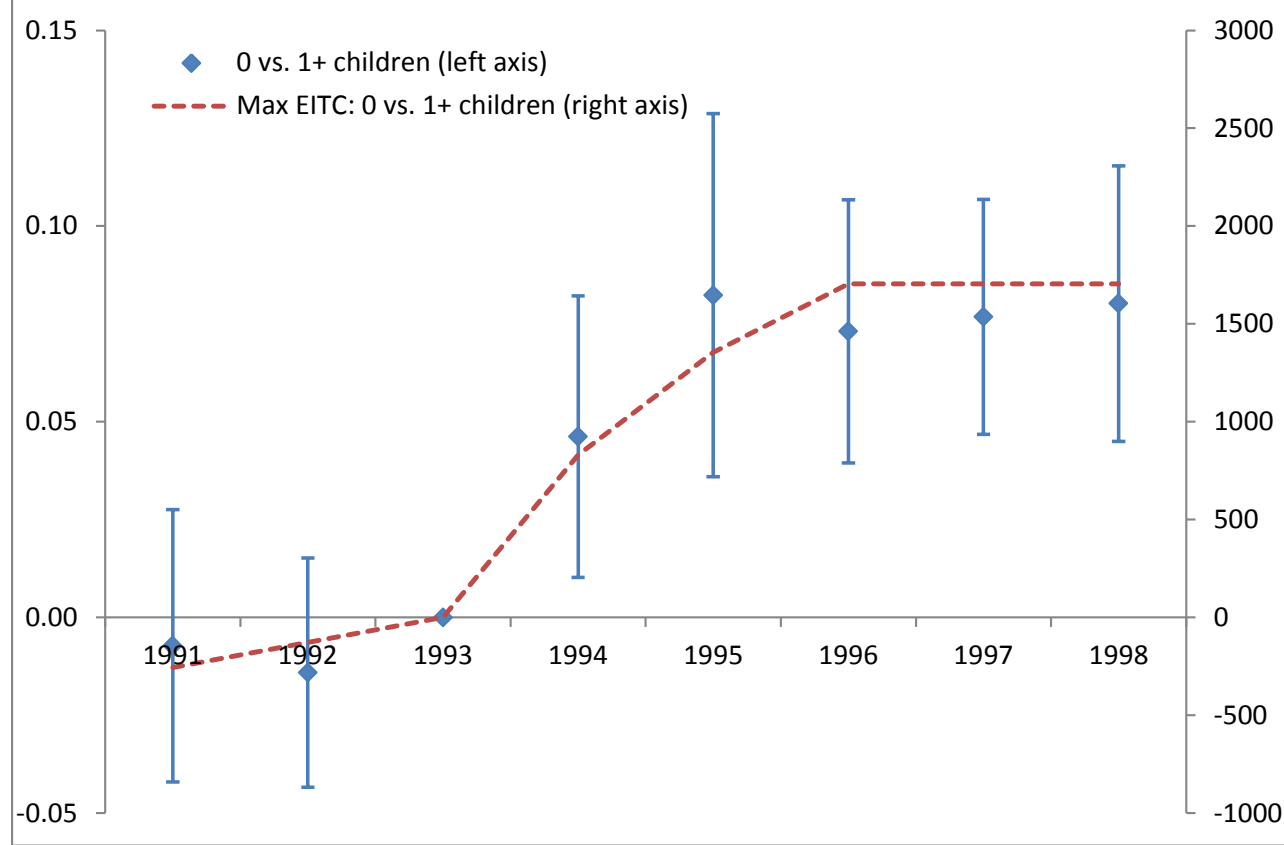

Notes: The sample includes single women, ages 24 through 48 with some college education or less from the 1992 through 1999 Current Population Survey (March). See equation (3) in text and data appendix for details. 95\% confidence intervals clustered on state.

Figure 10: Event Model Estimates of OBRA 93 on ATT Income Above 100\% of the Poverty Threshold, 1 vs 2+ Children

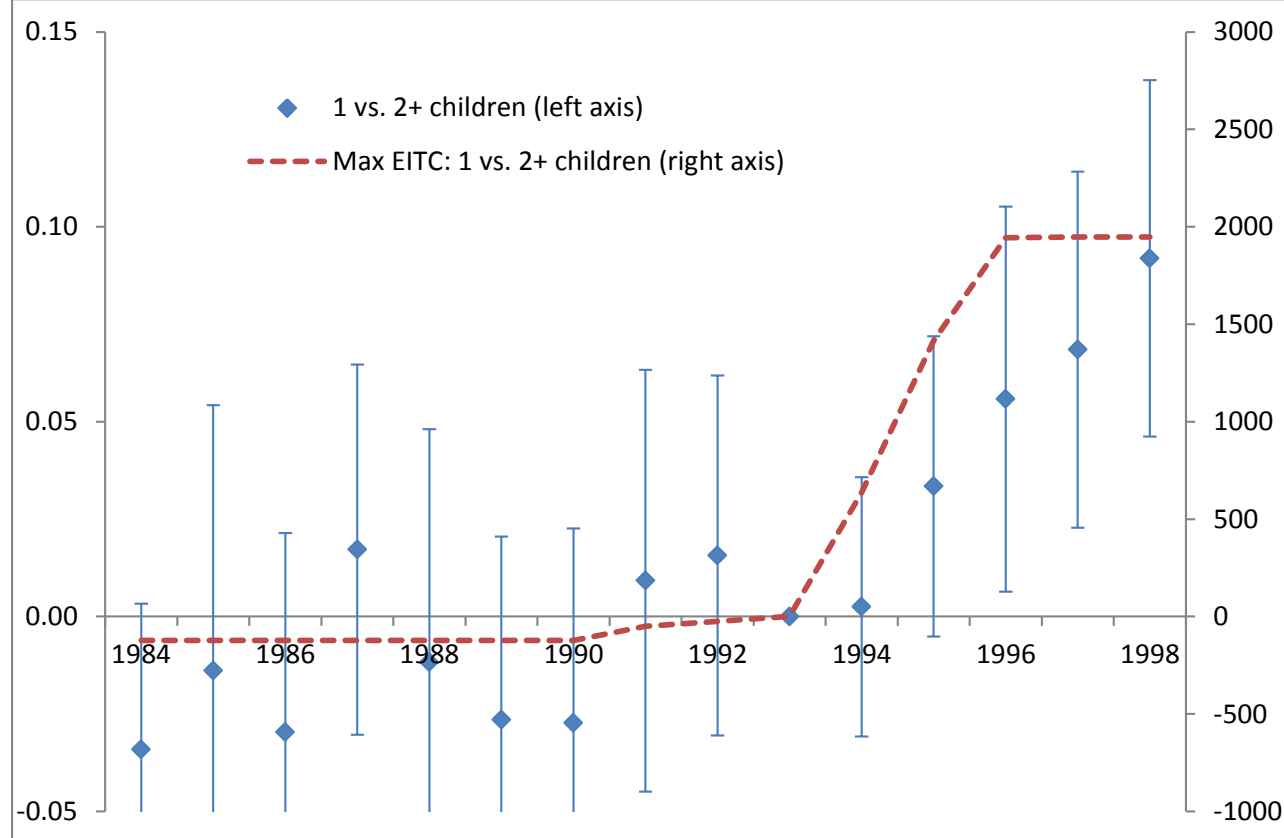

Notes: The sample includes single women with children, ages 24 through 48 with some college education or less from the 1985 through 1999 Current Population Survey (March). See equation (3) in text and data appendix for details. 95\% confidence intervals clustered on state. 
Figure 11: Difference-in-difference Estimates of OBRA 93 on ATT Income Above Multiples of the Federal Poverty Threshold, 0 vs 1+ Children

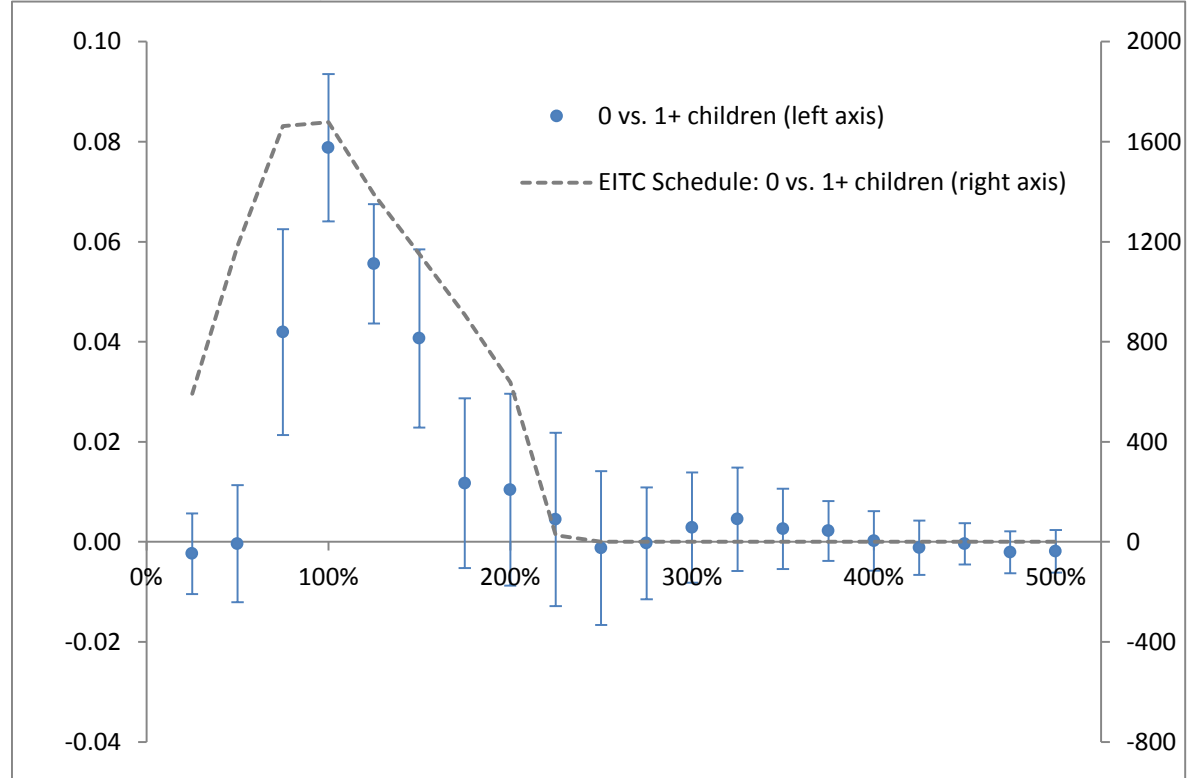

Notes: The sample includes single women, ages 24 through 48 with some college education or less from the 1992 through 1999 Current Population Survey (March). Each dot and whisker represents a single regression estimate and confidence interval. See equation (1) in text and data appendix for details. $95 \%$ confidence intervals clustered on state. The dashed line is the weighted change in EITC benefits for families with children versus those without children across the OBRA 93 expansion.

Figure 12: Difference-in-difference Estimates of OBRA 93 on ATT Income Above Multiples of the Federal Poverty Threshold, 1 vs 2+ Children

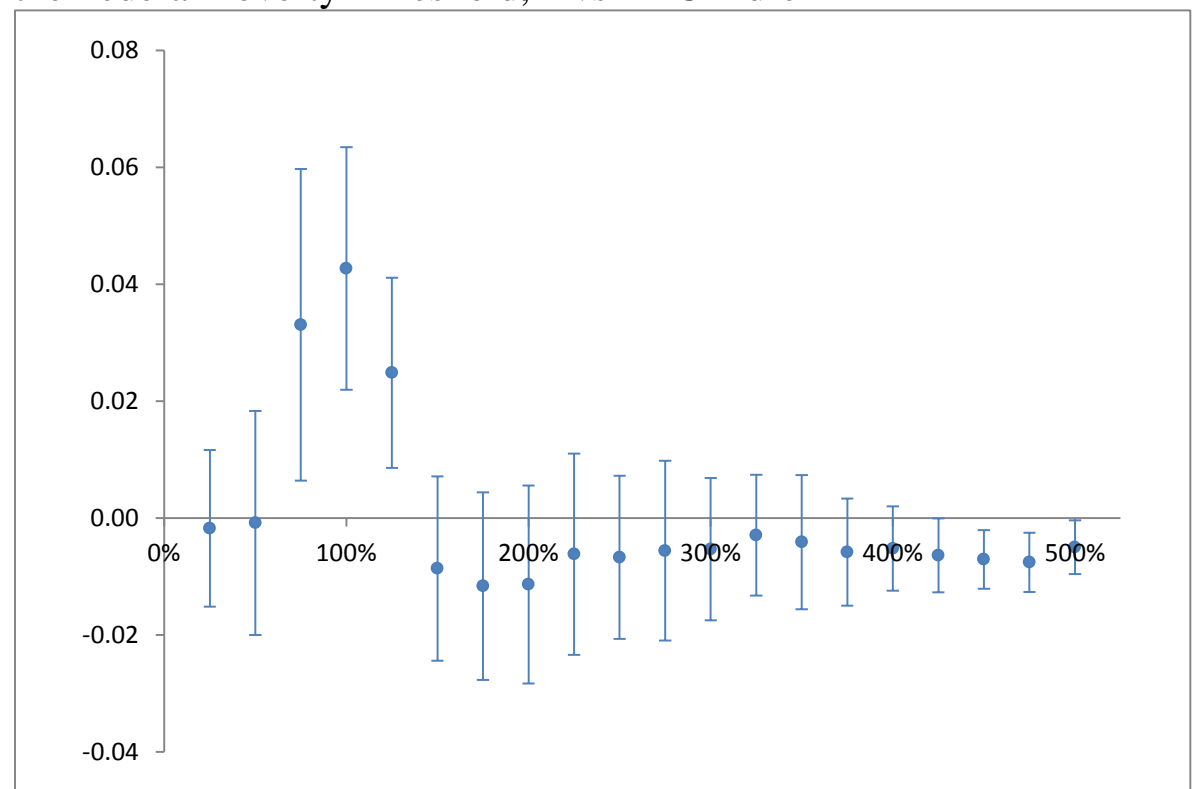

Notes: The sample includes single women with children, ages 24 through 48 with some college education or less from the 1992 through 1999 Current Population Survey (March). Each dot and whisker represents a single regression estimate and confidence interval. See equation (1) in text and data appendix for details. $95 \%$ confidence intervals clustered on state. 
Figure 13: Parameterized DD Estimates of TRA86, OBRA90 and OBRA93 on ATT Income Above Multiples of the Federal Poverty Threshold

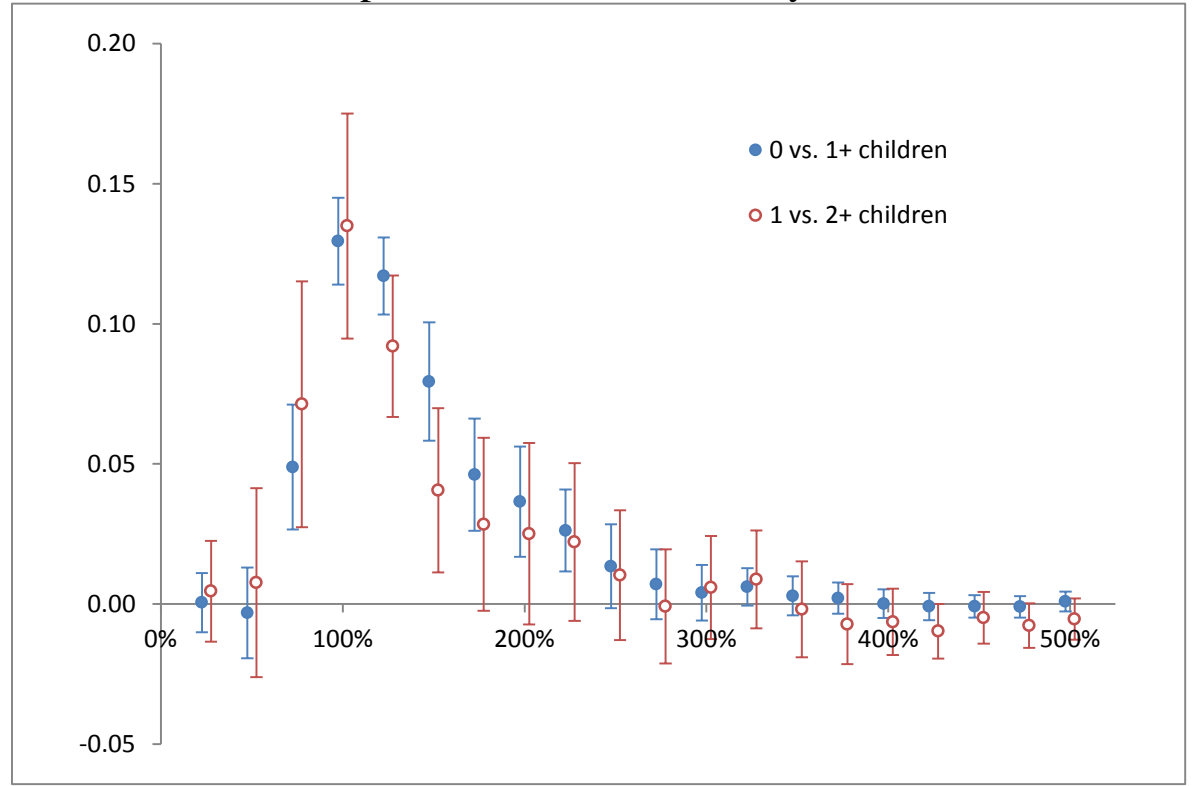

Notes: The sample includes single women, ages 24 through 48 with some college education or less from the 1985 through 1999 Current Population Survey (March). Each dot and whisker represents a single regression estimate and confidence interval. Simulated EITC constructed from 1983 CPS and TAXSIM. See equation (1) in text and data appendix for details. $95 \%$ confidence intervals clustered on state. 
Figure 14: The Effect of the EITC on the Aggregate Number of Children Above Multiples of the Federal Poverty Threshold, 2012

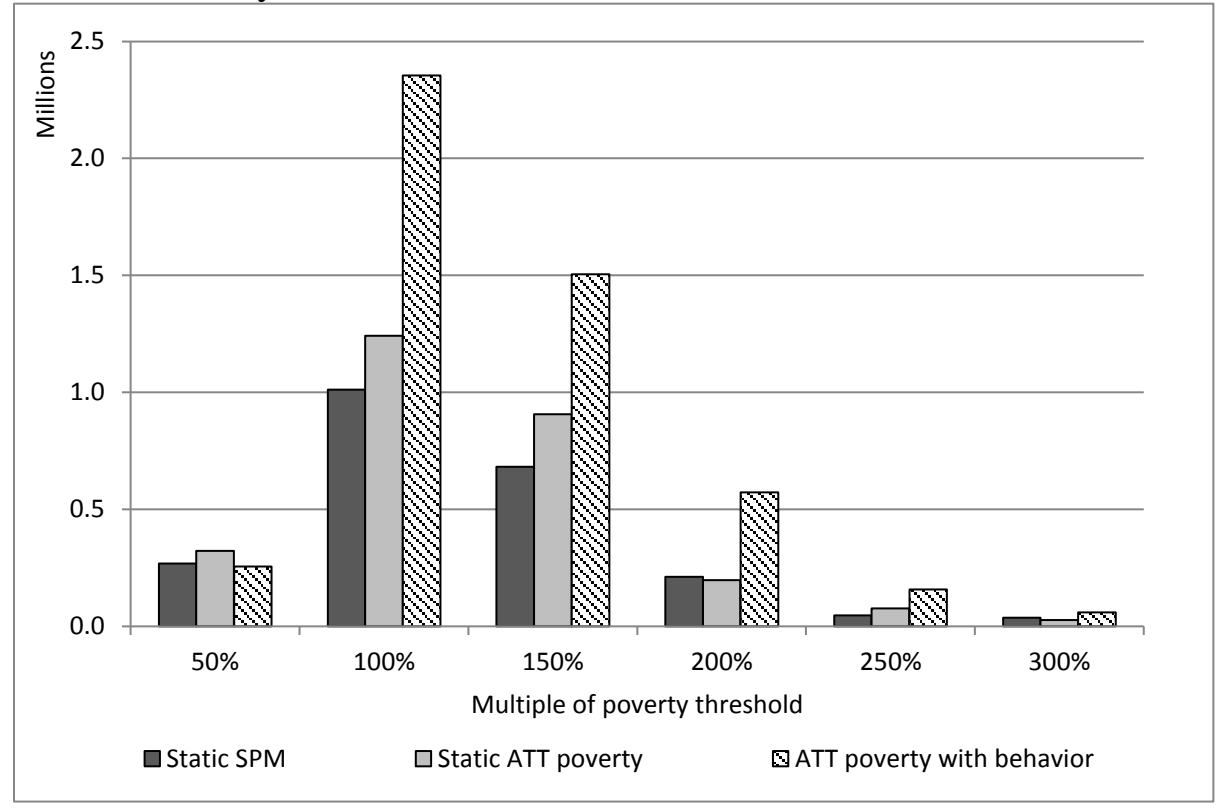

Figure 15: The Effect of the EITC on the Aggregate Number of Individuals Above Multiples of the Federal Poverty Threshold, 2012

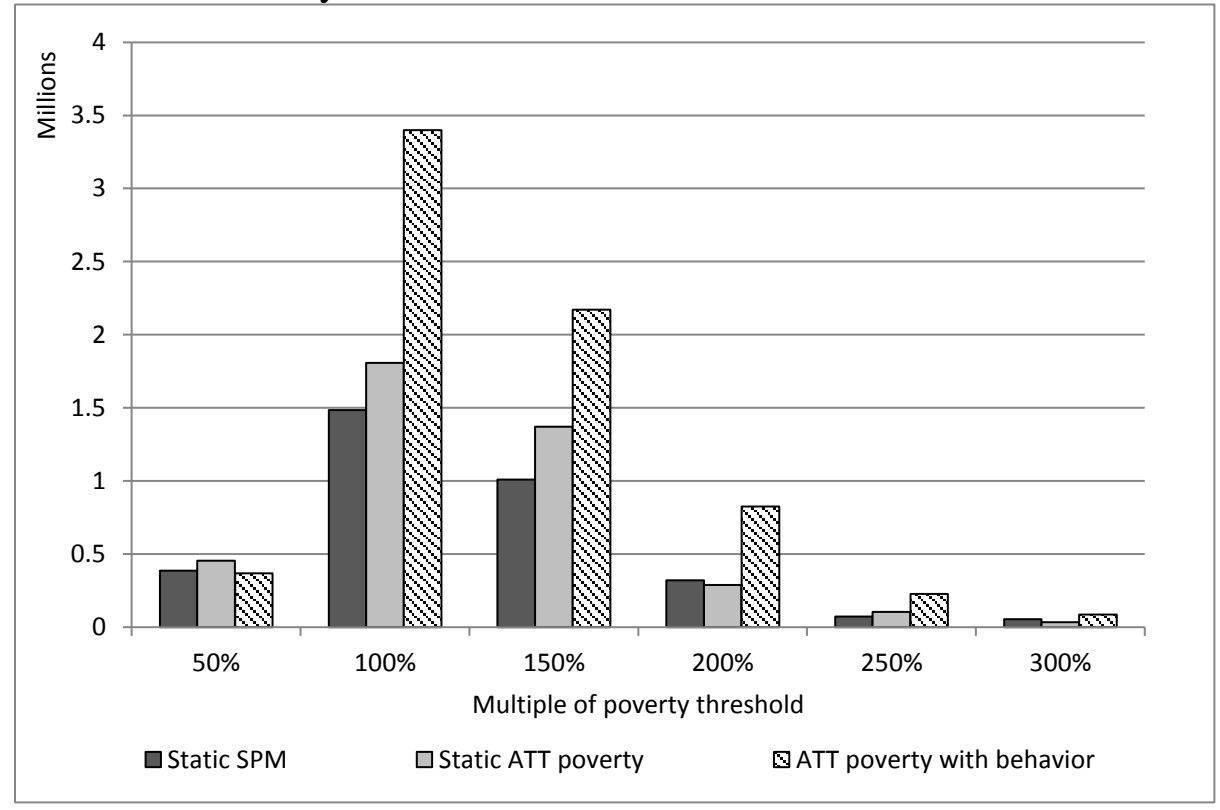

Notes: Counts include all individuals (figure 15) or children (Figure 14) within families with a single female parent whose age is between 24 and 48 with some college education or less from the 2013 Current Population Survey

(March) which corresponds to the 2012 calendar year. Each column represents the difference between including and removing the EITC from an aggregate poverty calculation. "Static SPM" uses Census provided supplemental poverty measure variables within the CPS to exclude the EITC. "Static ATT poverty" excludes the EITC alone from after-tax and income when calculating poverty status. "ATT poverty with behavior" uses fitted values from a regression estimating the comprehensive effects of the EITC on poverty status (see data appendix for details). 
Table 1: Tax filers, EITC Claimants and Multiples of the Federal Poverty Threshold

$\begin{array}{cccccc}\begin{array}{c}\text { Less than } \\ 50 \% \text { of }\end{array} & \text { Between } & \text { Between } & \text { Between } & \text { More than } & \\ \text { FPT } & \text { of FPT } & \text { of FPT } & \text { of FPT } & \text { FPT } & \text { All incomes } \\ \end{array}$

\begin{tabular}{|c|c|c|c|c|c|c|}
\hline \multicolumn{7}{|c|}{ Distribution of EITC claimants across multiples of the FPT } \\
\hline \multicolumn{7}{|l|}{ Single } \\
\hline With 1 child & 0.07 & 0.25 & 0.29 & 0.26 & 0.13 & 1.00 \\
\hline With 2 or more children & 0.05 & 0.16 & 0.41 & 0.28 & 0.11 & 1.00 \\
\hline \multicolumn{7}{|l|}{ Married filing joint } \\
\hline With 1 child & 0.06 & 0.19 & 0.25 & 0.33 & 0.17 & 1.00 \\
\hline With 2 or more children & 0.04 & 0.15 & 0.33 & 0.38 & 0.10 & 1.00 \\
\hline \multicolumn{7}{|c|}{ Share of filers who claim the EITC by multiples of the FPT } \\
\hline \multicolumn{7}{|c|}{ (1) } \\
\hline With 1 child & 0.76 & 0.89 & 0.87 & 0.88 & 0.21 & 0.62 \\
\hline With 2 or more children & 0.78 & 0.82 & 0.90 & 0.90 & 0.31 & 0.73 \\
\hline \multicolumn{7}{|l|}{ Married filing joint } \\
\hline With 1 child & 0.48 & 0.73 & 0.72 & 0.77 & 0.04 & 0.19 \\
\hline With 2 or more children & 0.49 & 0.69 & 0.77 & 0.78 & 0.03 & 0.22 \\
\hline
\end{tabular}

Notes: FPT is Federal Poverty Threshold. 2011 Statistics of Income Individual Complete Report File (tax year 2011). After tax income is computed as total income less taxes plus payments. Payroll taxes are imputed using total wages. In the top panel, each row should sum to 1.

Table 2: Difference-in-Difference Estimates of OBRA93 on Employment

\begin{tabular}{|c|c|c|c|c|}
\hline Model: & \multicolumn{2}{|c|}{0 vs. $1+$ Children } & \multicolumn{2}{|c|}{1 vs. $2+$ Children } \\
\hline (Year > 1993)* $(1+$ children $)$ & $\begin{array}{c}0.061 * * * \\
(0.01)\end{array}$ & $\begin{array}{c}0.047 * * * \\
(0.01)\end{array}$ & & \\
\hline$($ Year $>1993) *(2+$ children $)$ & & & $\begin{array}{c}0.062 * * * \\
(0.01)\end{array}$ & $\begin{array}{l}0.024 \\
(0.02)\end{array}$ \\
\hline Per $\$ 1000$ of federal EITC & 0.073 & 0.074 & 0.078 & 0.056 \\
\hline$\%$ impact & $8.6 \%$ & $8.8 \%$ & $9.9 \%$ & $7.0 \%$ \\
\hline Extensive margin elasticity & 0.36 & 0.37 & 0.45 & 0.32 \\
\hline $\begin{array}{l}\text { Observations } \\
\text { Mean of the dependent variable }\end{array}$ & $\begin{array}{c}50,508 \\
0.844\end{array}$ & $\begin{array}{c}50,508 \\
0.844\end{array}$ & $\begin{array}{c}25,101 \\
0.796\end{array}$ & $\begin{array}{c}25,101 \\
0.796\end{array}$ \\
\hline \multicolumn{5}{|l|}{ Controls } \\
\hline Demographics & $\mathrm{X}$ & $X$ & $\mathrm{X}$ & $X$ \\
\hline \# of children indicators & $\mathrm{X}$ & $\mathrm{X}$ & $\mathrm{X}$ & $X$ \\
\hline State * year indicators & $\mathrm{X}$ & $X$ & $\mathrm{X}$ & $X$ \\
\hline Simulated tax \& transfer benefits & & $\mathrm{X}$ & & $X$ \\
\hline Any AFDC waiver $* 1+$ children & & $\mathrm{X}$ & & \\
\hline Any AFDC waiver $* 2+$ children & & & & $X$ \\
\hline Unemp rate $* 1+$ children & & $\mathrm{X}$ & & \\
\hline Unemp rate $* 2+$ children & & & & $X$ \\
\hline
\end{tabular}

Notes: The sample includes single women, ages 24 through 48 with some college education or less from the 1992 through 1999 Current Population Survey (March). See text and data appendix for details. Standard errors clustered on state. Significance levels: $* 10 \%, * * 5 \%, * * * 1 \%$. 
Table 3: Parameterized DD Estimates of OBRA93 on Employment

\begin{tabular}{lcccc} 
Model: & \multicolumn{2}{c}{0 vs. 1+ Children } & \multicolumn{2}{c}{1 vs. 2+ Children } \\
\hline Simulated EITC $(\$ 1,000)$ & $0.132^{* * *}$ & $0.107^{* * *}$ & $0.146^{* * *}$ & $0.096^{* *}$ \\
& $(0.01)$ & $(0.01)$ & $(0.02)$ & $(0.04)$ \\
Per \$1000 of federal EITC & 0.076 & 0.072 & 0.082 & 0.076 \\
$\%$ impact & $9.0 \%$ & $8.5 \%$ & $10.3 \%$ & $9.6 \%$ \\
Extensive margin elasticity & 0.38 & 0.36 & 0.47 & 0.43 \\
Observations & 50,508 & 50,508 & 25,101 & 25,101 \\
Mean of the dependent variable & 0.844 & 0.844 & 0.796 & 0.796 \\
Controls & & & & $\mathrm{X}$ \\
Demographics & $\mathrm{X}$ & $\mathrm{X}$ & $\mathrm{X}$ & $\mathrm{X}$ \\
\# of children indicators & $\mathrm{X}$ & $\mathrm{X}$ & $\mathrm{X}$ & $\mathrm{X}$ \\
State * year indicators & $\mathrm{X}$ & $\mathrm{X}$ & $\mathrm{X}$ & $\mathrm{X}$ \\
Simulated tax \& transfer benefits & & $\mathrm{X}$ & & $\mathrm{X}$ \\
Any AFDC waiver * $1+$ children & & $\mathrm{X}$ & & $\mathrm{X}$ \\
Any AFDC waiver $* 2+$ children & & $\mathrm{X}$ & & \\
Unemp rate * $1+$ children & & & & \\
Unemp rate * $2+$ children & & & & \\
\hline
\end{tabular}

Notes: The sample includes single women, ages 24 through 48 with some college education or less from the 1992 through 1999 Current Population Survey (March). Simulated EITC constructed from 1983 CPS and TAXSIM. See text and data appendix for details. Standard errors clustered on state. Significance levels: *10\%, $* * 5 \%, * * * 1 \%$.

Table 4: Parameterized DD Estimates of TRA86, OBRA90 and OBRA93 on Employment

\begin{tabular}{|c|c|c|c|c|}
\hline \multirow{2}{*}{$\begin{array}{l}\text { Model: } \\
\text { Simulated EITC }(\$ 1,000)\end{array}$} & \multicolumn{2}{|c|}{0 vs. $1+$ Children } & \multicolumn{2}{|c|}{1 vs. $2+$ Children } \\
\hline & $\begin{array}{c}0.095 * * * \\
(0.01)\end{array}$ & $\begin{array}{c}0.076^{* * * *} \\
(0.01)\end{array}$ & $\begin{array}{c}0.139 * * * \\
(0.02)\end{array}$ & $\begin{array}{c}0.121 * * * \\
(0.03)\end{array}$ \\
\hline Per $\$ 1000$ of federal EITC & 0.062 & 0.052 & 0.082 & 0.082 \\
\hline$\%$ impact & $7.4 \%$ & $6.2 \%$ & $10.5 \%$ & $10.5 \%$ \\
\hline Extensive margin elasticity & 0.31 & 0.26 & 0.46 & 0.46 \\
\hline Observations & 96,204 & 96,204 & 47,215 & 47,215 \\
\hline Mean of the dependent variable & 0.835 & 0.835 & 0.776 & 0.776 \\
\hline \multicolumn{5}{|l|}{ Controls } \\
\hline Demographics & $\mathrm{X}$ & $\mathrm{X}$ & $\mathrm{X}$ & $\mathrm{X}$ \\
\hline \# of children indicators & $\mathrm{X}$ & $\mathrm{X}$ & $\mathrm{X}$ & $\mathrm{X}$ \\
\hline State $*$ year indicators & $\mathrm{X}$ & $\mathrm{X}$ & $\mathrm{X}$ & $\mathrm{X}$ \\
\hline Simulated tax \& transfer benefits & & $\mathrm{X}$ & & $\mathrm{X}$ \\
\hline Any AFDC waiver $* 1+$ children & & $\mathrm{X}$ & & \\
\hline Any AFDC waiver $* 2+$ children & & & & $\mathrm{X}$ \\
\hline Unemp rate $* 1+$ children & & $\mathrm{X}$ & & \\
\hline Unemp rate $* 2+$ children & & & & $\mathrm{X}$ \\
\hline
\end{tabular}

Notes: The sample includes single women, ages 24 through 48 with some college education from the 1985 through 1999 Current Population Survey (March). Simulated EITC constructed from 1983 CPS and TAXSIM. See text and data appendix for details. Standard errors clustered on state. Significance levels: *10\%, **5\%, ***1\%. 
Table 5: Difference-in-Difference Estimates of OBRA93 on ATT Income Above 100\% of the Federal Poverty Threshold

\begin{tabular}{|c|c|c|c|c|}
\hline \multirow{2}{*}{$\begin{array}{l}\text { Model: } \\
(\text { Year }>1993) *(1+\text { children })\end{array}$} & \multicolumn{2}{|c|}{0 vs. $1+$ Children } & \multicolumn{2}{|c|}{1 vs. $2+$ Children } \\
\hline & $\begin{array}{c}0.079 * * * \\
(0.01)\end{array}$ & $\begin{array}{c}0.081 * * * \\
(0.02)\end{array}$ & & \\
\hline$($ Year $>1993) *(2+$ children $)$ & & & $\begin{array}{c}0.043 * * * \\
(0.01)\end{array}$ & $\begin{array}{l}0.020 \\
(0.01)\end{array}$ \\
\hline Per $\$ 1000$ of federal EITC & 0.094 & 0.129 & 0.054 & 0.047 \\
\hline$\%$ impact & $14.1 \%$ & $19.2 \%$ & $9.1 \%$ & $7.8 \%$ \\
\hline Extensive margin elasticity & 0.64 & 0.84 & 0.48 & 0.41 \\
\hline Observations & 50,508 & 50,508 & 25,101 & 25,101 \\
\hline Mean of the dependent variable & 0.670 & 0.670 & 0.601 & 0.601 \\
\hline \multicolumn{5}{|l|}{ Controls } \\
\hline Demographics & $\mathrm{X}$ & $\mathrm{X}$ & $\mathrm{X}$ & $\mathrm{X}$ \\
\hline \# of children indicators & $\mathrm{X}$ & $\mathrm{X}$ & $\mathrm{X}$ & $\mathrm{X}$ \\
\hline State $*$ year indicators & $\mathrm{X}$ & $\mathrm{X}$ & $\mathrm{X}$ & $\mathrm{X}$ \\
\hline Simulated tax \& transfer benefits & & $\mathrm{X}$ & & $\mathrm{X}$ \\
\hline Any AFDC waiver $* 1+$ children & & $\mathrm{X}$ & & \\
\hline Any AFDC waiver $* 2+$ children & & & & $\mathrm{X}$ \\
\hline Unemp rate $* 1+$ children & & $\mathrm{X}$ & & \\
\hline Unemp rate $* 2+$ children & & & & $\mathrm{X}$ \\
\hline
\end{tabular}

Notes: The sample includes single women, ages 24 through 48 with some college education or less from the 1992 through 1999 Current Population Survey (March). See text and data appendix for details. Standard errors clustered on state.

Significance levels: $* 10 \%, * * 5 \%, * * * 1 \%$.

Table 6: Parameterized DD Estimates of TRA86, OBRA90 and OBRA93 on ATT Income Above $100 \%$ of the Federal Poverty Threshold

\begin{tabular}{lcccc}
\hline Model: & \multicolumn{2}{c}{0 vs. 1+ Children } & \multicolumn{2}{c}{1 vs. 2+ Children } \\
\hline Simulated EITC $(\$ 1,000)$ & $0.129^{* * *}$ & $0.133^{* * *}$ & $0.135^{* * *}$ & $0.117^{* * *}$ \\
& $(0.01)$ & $(0.01)$ & $(0.02)$ & $(0.03)$ \\
Per $\$ 1000$ of federal EITC & 0.084 & 0.091 & 0.079 & 0.079 \\
$\%$ impact & $12.8 \%$ & $13.8 \%$ & $13.9 \%$ & $13.8 \%$ \\
Extensive margin elasticity & 0.57 & 0.61 & 0.68 & 0.67 \\
Observations & 96,204 & 96,204 & 47,215 & 47,215 \\
Mean of the dependent variable & 0.658 & 0.658 & 0.571 & 0.571 \\
Controls & & & & \\
Demographics & $\mathrm{X}$ & $\mathrm{X}$ & $\mathrm{X}$ & $\mathrm{X}$ \\
\# of children indicators & $\mathrm{X}$ & $\mathrm{X}$ & $\mathrm{X}$ & $\mathrm{X}$ \\
State * year indicators & $\mathrm{X}$ & $\mathrm{X}$ & $\mathrm{X}$ & $\mathrm{X}$ \\
Simulated tax \& transfer benefits & & $\mathrm{X}$ & & $\mathrm{X}$ \\
Any AFDC waiver * $1+$ children & & & & $\mathrm{X}$ \\
Any AFDC waiver * 2+ children & & $\mathrm{X}$ & & $\mathrm{X}$ \\
Unemp rate * $1+$ children & & & & \\
Unemp rate * $2+$ children & & &
\end{tabular}

Notes: The sample includes single women, ages 24 through 48 with some college education or less from the 1985 through 1999 Current Population Survey (March). See text and data appendix for details. Standard errors clustered on state. Significance levels: $* 10 \%, * * 5 \%, * * * 1 \%$. 


\title{
APPENDIX FOR
}

Effective Policy for Reducing Inequality:

The Earned Income Tax Credit and the Distribution of Income

\author{
Hilary W. Hoynes \\ and \\ Ankur J. Patel
}




\section{Data Appendix}

Our primary source of data is the Current Population Survey March Annual Demographic File and Income Supplement (CPS). We use survey years 1985 through 2014 for the main analysis. We download this dataset from the IPUMS-CPS database (King, Ruggles, Alexander, Flood, Genadek, Schroeder, Trampe and Vick 2010).

We limit the sample to single women. Single is defined as separated, divorced, widowed, or never married. We limit the sample to women between the ages of 24 and 48 . We do not use individuals under the age of 24 because they may be claimed as an EITC qualifying child if they are enrolled in school, clouding the work incentive. We drop women who did not work during the previous year because of illness, disability or school enrollment. These women have visibly different incentives entering their work decision. We drop those living in Hawaii or Alaska.

For the main analysis, we restrict to those with some college or less. ${ }^{1}$ When restricting the sample based on education, others have focused on those with a high school degree or less (Meyer and Rosenbaum 2000, Eissa and Hoynes 2006). Excluding women who have some college education may ignore an increasingly important part of the EITC eligible population. Appendix figure 1 plots the share in education group $\mathrm{X}$ among those who are EITC eligible minus the share in education group $\mathrm{X}$ among those who are ineligible, where $\mathrm{X}$ is an education group (less than a high school degree, high school graduate, some college, college graduate, post college education). A larger value indicates that the distribution of those in a particular education group favors eligibility. Appendix figure 1 indicates that over the sample period, those who have some college education make up more of the total eligible population. This issue is related but different from stability over time across treatment and control groups required by the difference in difference estimator. ${ }^{2}$

Pre-tax income information available in the CPS includes earnings, self-employed earnings, AFDC/TANF, General Assistance, UI, Worker's Compensation, veteran's benefits, SSI, social security, rail road retirement benefits, survivor benefits, disability benefits, retirement income, interest, dividends, income from rent, alimony, child support, and contributions from others outside of the household (Meyer, Mok and Sullivan 2008). The CPS also collects information on income from food stamps and heat subsidies at the household level. We allocate these to tax units using their proportional size within the household.

The CPS does not contain a consistent record of observed tax information. ${ }^{3}$ We use income and family structure in the CPS to calculate federal and state income taxes and payroll taxes using the NBER TAXSIM program (Feenberg and Coutts 1993). Before we preform any restrictions on the data, we construct tax units by linking EITC qualified children to the youngest mother, grandmother or great-grandmother in the CPS-defined family between the ages 24 and 48 . A

\footnotetext{
${ }^{1}$ Prior to 1992, this is defined as those with fewer than 4 years of college. After 1991, this is defined as those without a college degree.

${ }^{2}$ See appendix table 2 for DD estimates that include women of different education levels.

${ }^{3}$ In some years, the CPS does contain calculated income taxes.
} 
qualified child is defined as under the age of 18 or between 19 and 23 and in school. ${ }^{4}$ We link child to parent using the family linkage variables included in the IPUMS-CPS (IPUMS-USA 2014). IPUMS constructs variables that allow us to identify how members of the household are related to each other. Income information is aggregated up to the level of this tax unit. We then pass this tax unit's income and dependent information through TAXSIM. We assume that these tax units take the standard deduction ${ }^{5}$, are fully compliant and that they would take up the EITC if eligible. ${ }^{6}$ We are unable to include "above the line" deductions that are not included in the CPS, such as education or moving expenses. It is important to remember that these taxes are calculated using all observed taxpayer information for each time period. This is not the case with the "simulated" taxes and transfers described below.

A woman is employed if she collects positive earned income anytime during the tax year. This includes self-employment earnings. After-tax and transfer income is the sum of the cash and non-cash income available in the CPS, minus federal and state income taxes as well as payroll taxes. We do not adjust after-tax and transfer income for non-cash benefits such as Medicaid, general assistance, housing assistance and other public programs.

Simulated taxes and transfers are summary measures of policy changes. For simulated income taxes, we begin with a sample of women from the survey year 1983 (applying the same restrictions described above). We then replicate this sample for each year in the sample, and adjust each source of income for inflation. Finally, we pass this dataset through NBER TAXSIM and take average tax values by tax year and family size.

We use the same sample and a similar process to calculate simulated welfare transfers (Hoynes and Luttmer 2011). We calculate AFDC/TANF benefits using a simple benefit formula:

$$
B=G-\tau \times(E-D)-U
$$

where $B$ is the amount of the benefit, $G$ is the maximum benefit, $\tau$ is the tax rate (or the benefit reduction rate), $\mathrm{E}$ is countable taxpayer earnings, $\mathrm{D}$ is the flat earnings disregard, and $\mathrm{U}$ is taxpayer unearned income. The policy parameters are $G, \tau$, and $D$. These parameters may vary by state, year and family size. We compiled these parameters from several sources (US House of Representatives, various years, UK Center for Poverty Research 2013, Urban Institute 2013). The calculator does not take into account time limits or work requirements (before or after welfare reform). As was the case with taxes, we use fixed family information to calculate the benefit, and then collapse to the cell level (state, year, family size).

Prior to welfare reform, states were allowed to test changes to AFDC if they applied for and received a waiver from the federal government (Crouse 1999). There were many different types

\footnotetext{
${ }^{4}$ There are other rules for a qualifying child that we cannot observe and exclude: A child must live with the taxpayer for more than half the year, has a valid social security number, and is not claimed as a dependent by another taxpayer (IRS 2013).

${ }^{5}$ Among those most likely to receive a refundable credit, the share itemizing deductions is very small (Toder and Baneman 2012).

${ }^{6}$ EITC participation is high, with more than $80 \%$ of those who are eligible participating in the program during this period (Scholz 1994, Maynard and Dollins 2002).
} 
of waivers, but they fell into 6 major categories: Work and training requirements, time limits on welfare receipt, family caps provisions, expanded income disregards, increased resource limits, Medicaid assistance for the transition to work, expanded eligibility for two-parent families, and improved child support enforcement (HHS 1997). Our waiver indicator is equal to one if a state has had any waiver based on the date of first major welfare waiver (Bitler, Gelbach and Hoynes 2006). The waiver control is allowed to vary by family size (either no children versus $1+$ children, or one versus two or more children).

The Federal Poverty Threshold (FPT) varies by year and family size and is adjusted for inflation (Census 2014). In private correspondence with Census, we have confirmed that there are two errors in the thresholds: The value for a single parent family with one child in 1993 should be $\$ 9,960$. The value for a two parent family with three children should be $\$ 17,245$. These values have subsequently been corrected. ${ }^{7}$

Nominal dollars are converted to real dollars using the annual CPI-U. ${ }^{8}$

Unemployment rates by state and year come from the BLS Local Area Unemployment Statistics program (BLS 2013). When used as a control, we allow the effect of the unemployment to vary by family size.

In addition to the reduced form, we have several other ways that we present the effect of the EITC. First, we rescale the reduced form using a first stage. In this first stage, the RHS remains exactly the same as the reduced form, but the dependent variable is changed to the federal EITC. This federal EITC is calculated by NBER TAXSIM and uses current income and taxpayer characteristics (it is not the simulated EITC described above). The rescaled effect is in terms of federal EITC dollars. We present this estimate in $\$ 1,000$ increments for visual ease. We refer to this estimate as "Per $\$ 1,000$ of policy-induced federal EITC". Second, we divide the indirect least squares estimate by the dependent mean to get a percent impact. This mean is sample specific. We refer to this estimate as the "\% impact". Third, we implement the extensive margin elasticity in Chetty, Guren, Manoli and Weber (2013). They define this elasticity as

$$
\epsilon=\frac{\ln \left(\mathrm{P}_{0}^{\mathrm{T}}+\beta^{\mathrm{ILS}}\right)-\ln \left(\mathrm{P}_{0}^{\mathrm{T}}\right)}{\ln \left(\mathrm{I}_{1}^{\mathrm{T}, \mathrm{W}}-\mathrm{I}_{1}^{\mathrm{T}, \mathrm{N}}\right)-\ln \left(\mathrm{I}_{0}^{\mathrm{T}, \mathrm{W}}-\mathrm{I}_{0}^{\mathrm{T}, \mathrm{N}}\right)}
$$

where $\beta^{\mathrm{ILS}}$ is the indirect least squares estimate, $\mathrm{P}_{0}^{\mathrm{T}}$ is average participation in the pre-treatment period (subscript 0 ) among the treated group (superscript $\mathrm{T}$ ), $\mathrm{I}_{1}^{\mathrm{T}, \mathrm{W}}$ is average after-tax and transfer income (ATTI) in the post-treatment period among the treated group who are working (superscript W), $\mathrm{I}_{1}^{\mathrm{T}, \mathrm{N}}$ is average ATTI in the post-treatment period among the treated group who are not working, $\mathrm{I}_{0}^{\mathrm{T}, \mathrm{W}}$ is average ATTI in the pre-treatment period among the treated group who are working, and $\mathrm{I}_{0}^{\mathrm{T}, \mathrm{N}}$ is average ATTI in the pre-treatment period among the treated group who are not working. Intuitively, we can think of this elasticity estimate as the log change in labor

\footnotetext{
${ }^{7}$ December 13, 2014: https://www.census.gov/hhes/www/poverty/data/threshld/thresh93.html

${ }^{8}$ Consumer Price Index - All Urban Consumers, series CUUR0000SA0, US city average, all items, chained to 1982-84, annual (BLS 2014).
} 
force participation due to the EITC over the log change in after-tax and transfer income from working induced by the EITC. In addition to labor force participation, we also explore the distribution of after-tax and transfer income using multiples of the federal poverty threshold. In those cases we replace $\mathrm{P}_{0}^{\mathrm{T}}$ with $\mathrm{S}_{0}^{\mathrm{T}, 100 \%}$, the share of taxpayers above $100 \%$ of the federal poverty threshold in the pre-treatment period, among the treated group.

In section 7, we use three measures of poverty to estimate the aggregate number of individuals and children who are above federal poverty threshold multiples (50\%, 100\%, 150\% and 200\%). First, we use supplemental poverty measure-related variables provided by the Census to calculate static SPM poverty status with and without EITC income within our sample of single women. We determine after-tax and transfer income poverty status in a similar way, using family-level variables to calculate the EITC and the appropriate federal poverty threshold. We aggregate using the appropriate weights (all individuals, or just children). Second, we integrate our estimates into a measure of poverty, "ATTI poverty with behavior," in the following way: First, we extend the parameterized difference-in-difference model (equation 2) to include all tax years between 1984 and 2013. The outcome is equal to one if a family's after-tax and transfer income is above a multiple of the poverty threshold. We use the conservative control set, which includes controls for business cycles and other tax and transfer programs (such as those used in column 2 of table 6). Second, we predict fitted values with and without the simulated EITC. By excluding the measure of EITC policy expansions, we predict the probability a family is above a poverty threshold in a world without the EITC, based on observable characteristics. Finally, we multiply the average share of the fitted values in both scenarios by the appropriate weights and take the difference.

\section{Appendix References}

Bitler, Marianne, Jonah Gelbach and Hilary Hoynes (2006). "The Impact of Welfare Reform on Children's Living Arrangements," Journal of Human Resources, Volume 41, Number 1, pp. 1-27.

Bureau of Labor Statistics (2014). "CPI." http://www.bls.gov/cpi/.

--- (2013). “Local Area Unemployment Statistics.” http://www.bls.gov/lau/.

Crouse, Gil (1999). "State Implementation of Major Changes to Welfare Policies, 1992-1998," US Department of Health and Human Services, Assistant Secretary for Planning and Evaluation. http://aspe.hhs.gov/hsp/waiver-policies99/policy_cea.htm.

Feenberg, Daniel, and Elisabeth Coutts (1993). "An Introduction to the TAXSIM Model." Journal of Policy Analysis and Management, 12 (1): 189-194.

IPUMS-USA (2014). “Family Interrelationships,” IPUMS Documentation: User's Guide. https://usa.ipums.org/usa/chapter5/chapter5.shtml.

King, Miriam, Steven Ruggles, J. Trent Alexander, Sarah Flood, Katie Genadek, Matthew B. Schroeder, Brandon Trampe, and Rebecca Vick (2010). "Integrated Public Use Microdata Series, Current Population Survey: Version 3.0," [Machine-readable database]. Minneapolis: University of Minnesota. 
Maynard, Mike, and David Dollins (2002). "Participation in the Earned Income Tax Credit Program for Tax Year 1996 (Research Project 12.26).” Internal Revenue Service, SB/SE Research.

Meyer, Bruce D., Wallace K.C. Mok and James X. Sullivan (2008). "The Under Reporting of Transfers in Household Surveys: Its Nature and Consequences," NBER Working Paper Series, no. 15181, September.

Scholz, John Karl (1994). "The Earned Income Tax Credit: Participation, Compliance, and Anti Poverty Effectiveness." National Tax Journal, 47 (1): 63-87.

Toder, Eric, and Daniel Baneman (2012). "Distributional Effects of Individual Income Tax Expenditures: An Update.” Washington, DC: Urban-Brookings Tax Policy Center.

University of Kentucky Center for Poverty Research (2013). "National Dataset," July 2013, http://www.ukcpr.org/EconomicData/Copy\%20of\%20UKCPR_National_Data_Set_07_0 1_13.xlsx.

Urban Institute (2013). "Welfare Rules Database." http://anfdata.urban.org/wrd/Query/query.cfm.

U.S. House of Representatives (various years). "Background Material and Data on Programs within the Jurisdiction of the House Committee on Ways and Means." 
Appendix Figure 1: EITC Eligible vs Ineligible By Education Group

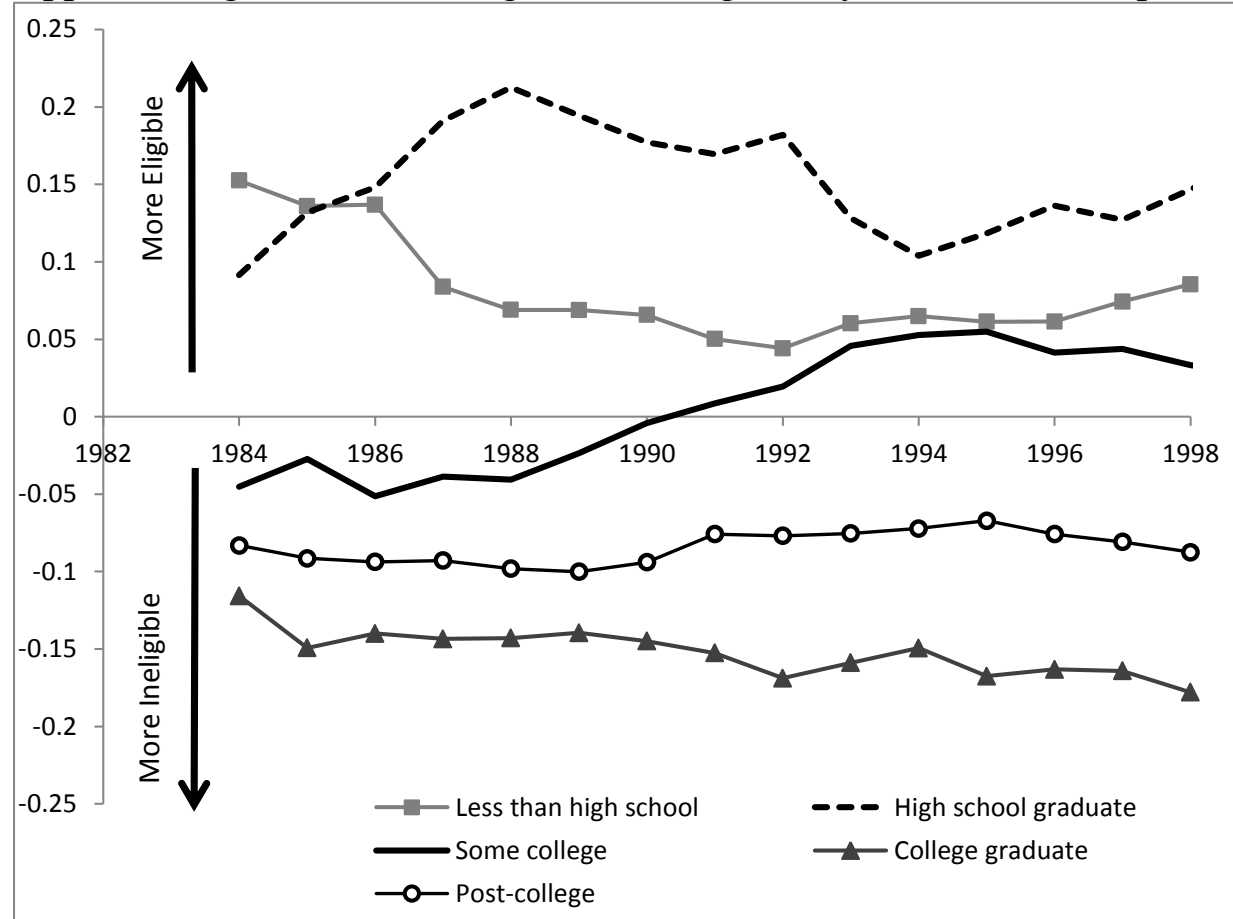

Notes: All other sample restrictions apply (see data appendix).

Appendix Figure 2: Event Model Estimates of TRA86, OBRA90 and OBRA93 on Employment

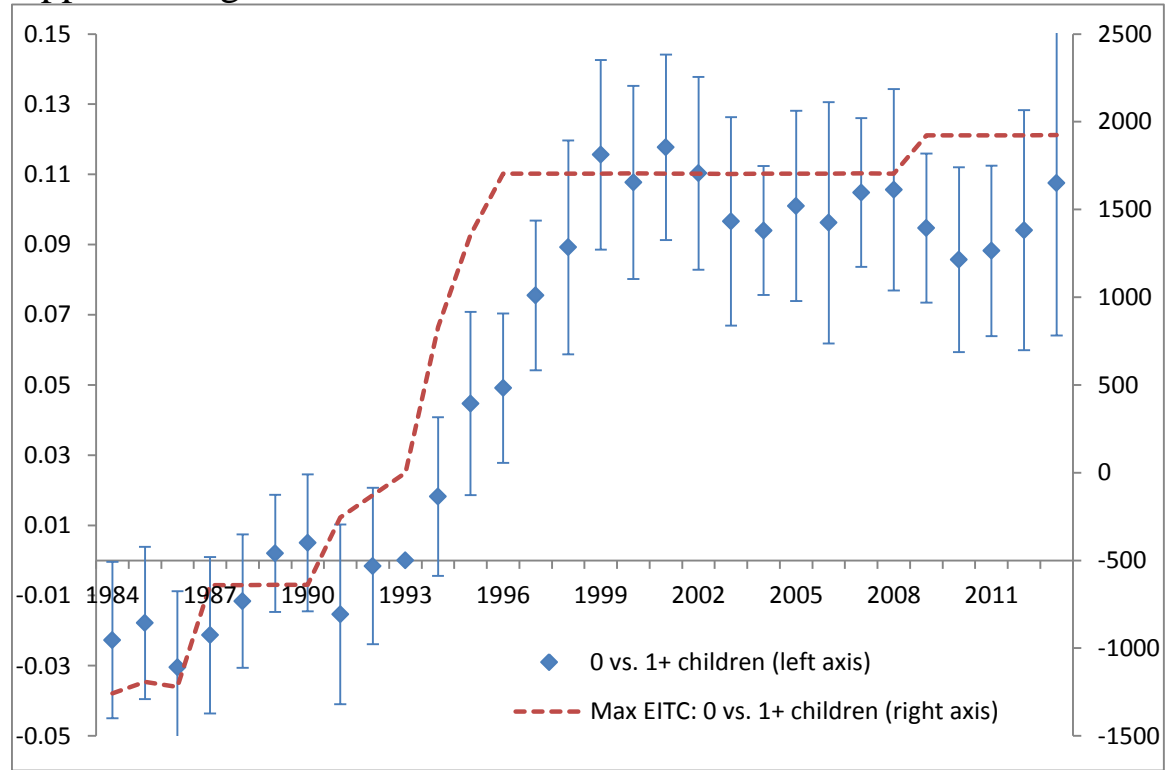

Notes: The sample includes single women, ages 24 through 48 with some college education or less from the 1985 through 2014 Current Population Survey (March). See equation (3) in text and data appendix for details. 95\% confidence intervals clustered on state. 
Appendix Figure 3: Event Model Estimates of TRA86, OBRA90 and OBRA93 on Employment by family size

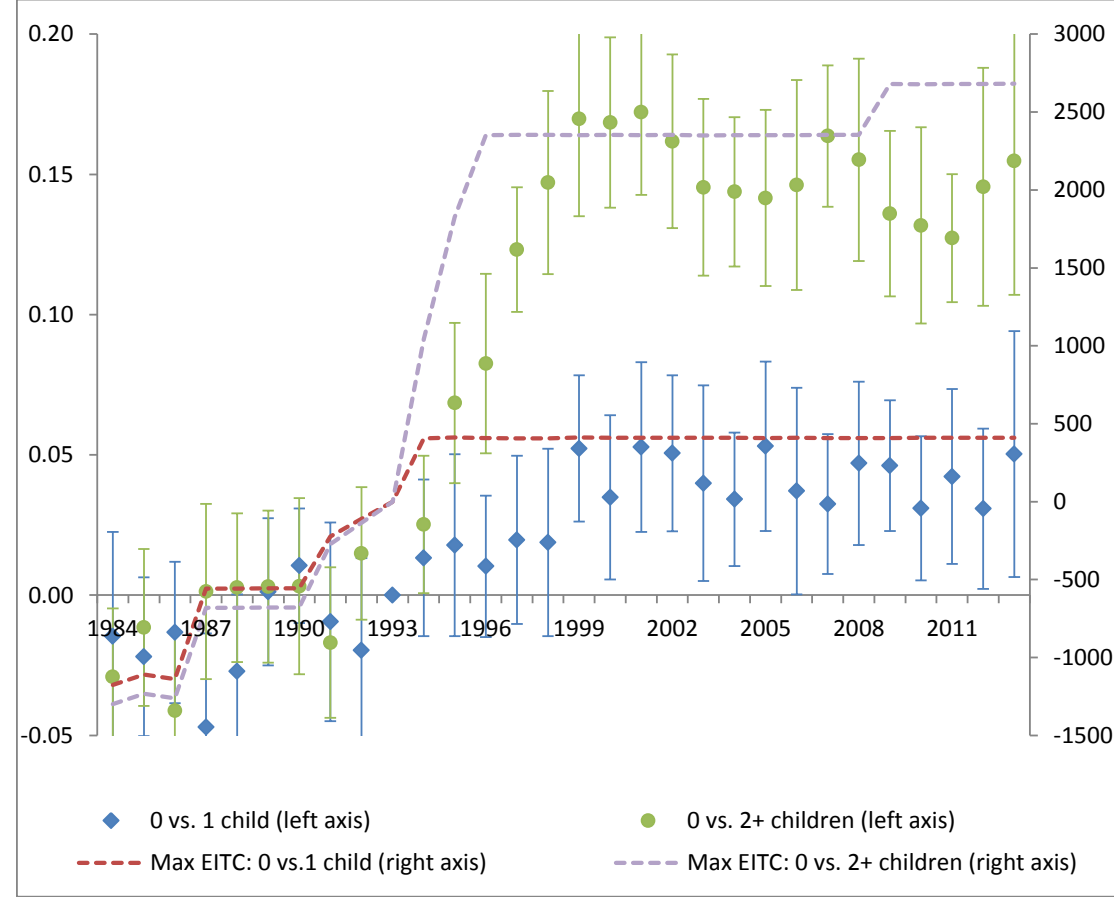

Notes: The sample includes single women, ages 24 through 48 with some college education or less from the 1985 through 2014 Current Population Survey (March). See equation (3) in text and data appendix for details. $95 \%$ confidence intervals clustered on state.

Appendix Figure 4: Event Model Estimates of TRA86, OBRA90 and OBRA93 on Employment, 1 vs $2+$ Children

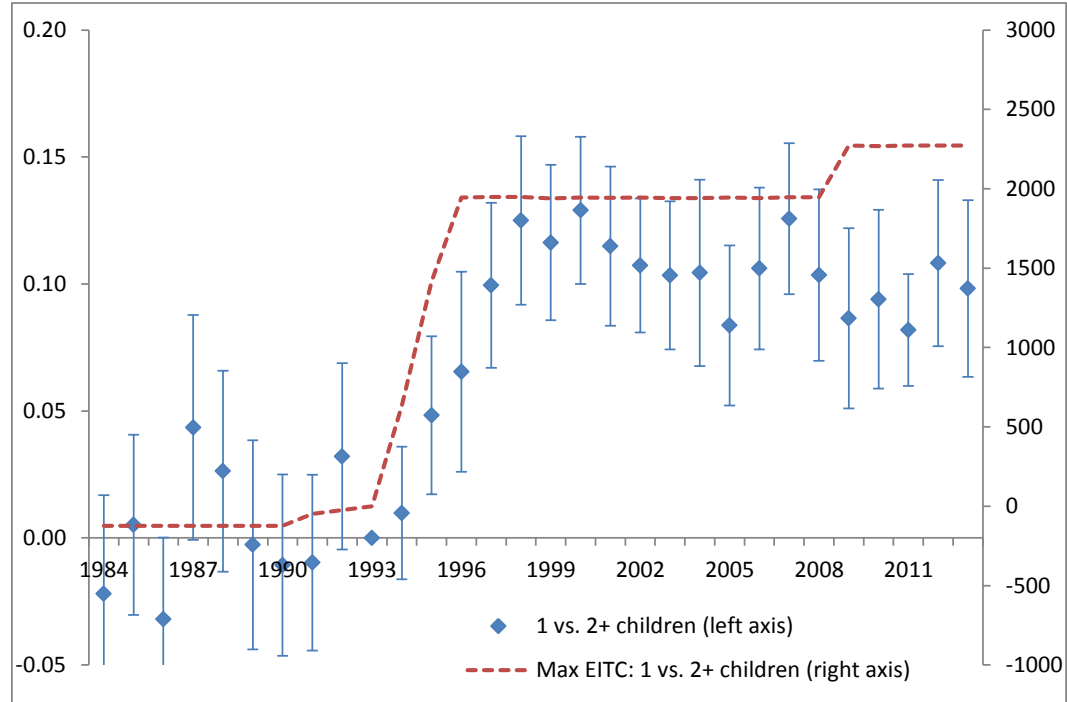

Notes: The sample includes single women with children, ages 24 through 48 with some college education or less from the 1985 through 2014 Current Population Survey (March). See equation (3) in text and data appendix for details. 95\% confidence intervals clustered on state. 
Appendix Figure 5: Event Model Estimates of TRA86, OBRA90 and OBRA93 on ATT Income Above $100 \%$ of the Poverty Threshold

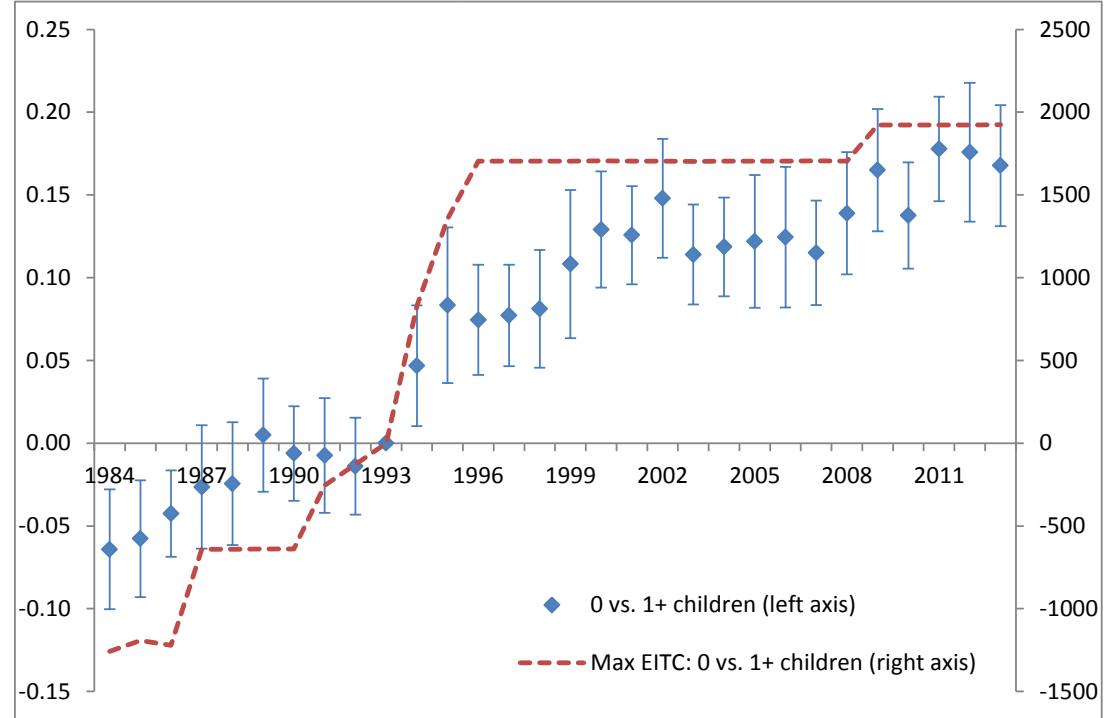

Notes: The sample includes single women, ages 24 through 48 with some college education or less from the 1985 through 2014 Current Population Survey (March). See equation (3) in text and data appendix for details. $95 \%$ confidence intervals clustered on state.

Appendix Figure 6: Event Model Estimates of TRA86, OBRA90 and OBRA93 on ATT Income Above $100 \%$ of the Poverty Threshold by family size

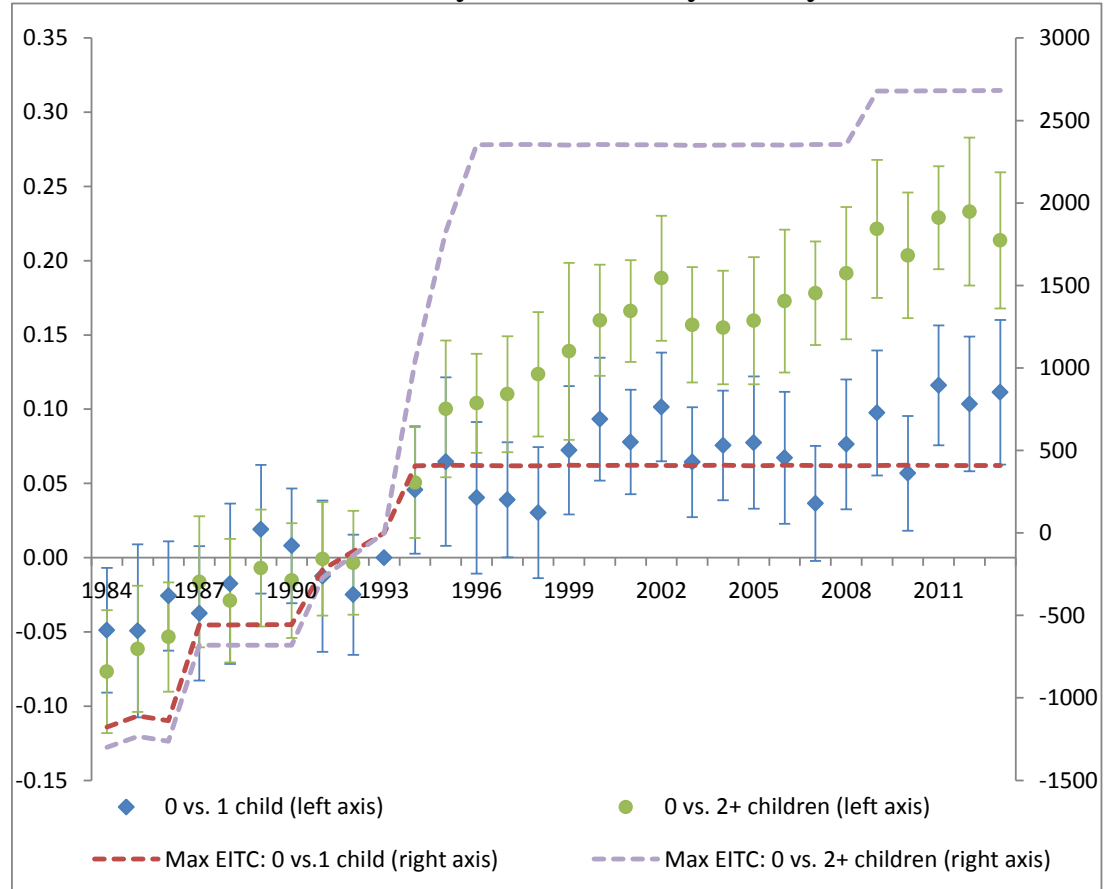

Notes: The sample includes single women, ages 24 through 48 with some college education or less from the 1985 through 2014 Current Population Survey (March). See equation (3) in text and data appendix for details. 95\% confidence intervals clustered on state. 
Appendix Figure 7: Event Model Estimates of TRA86, OBRA90 and OBRA93 on ATT Income Above $100 \%$ of the Poverty Threshold, 1 vs $2+$ Children

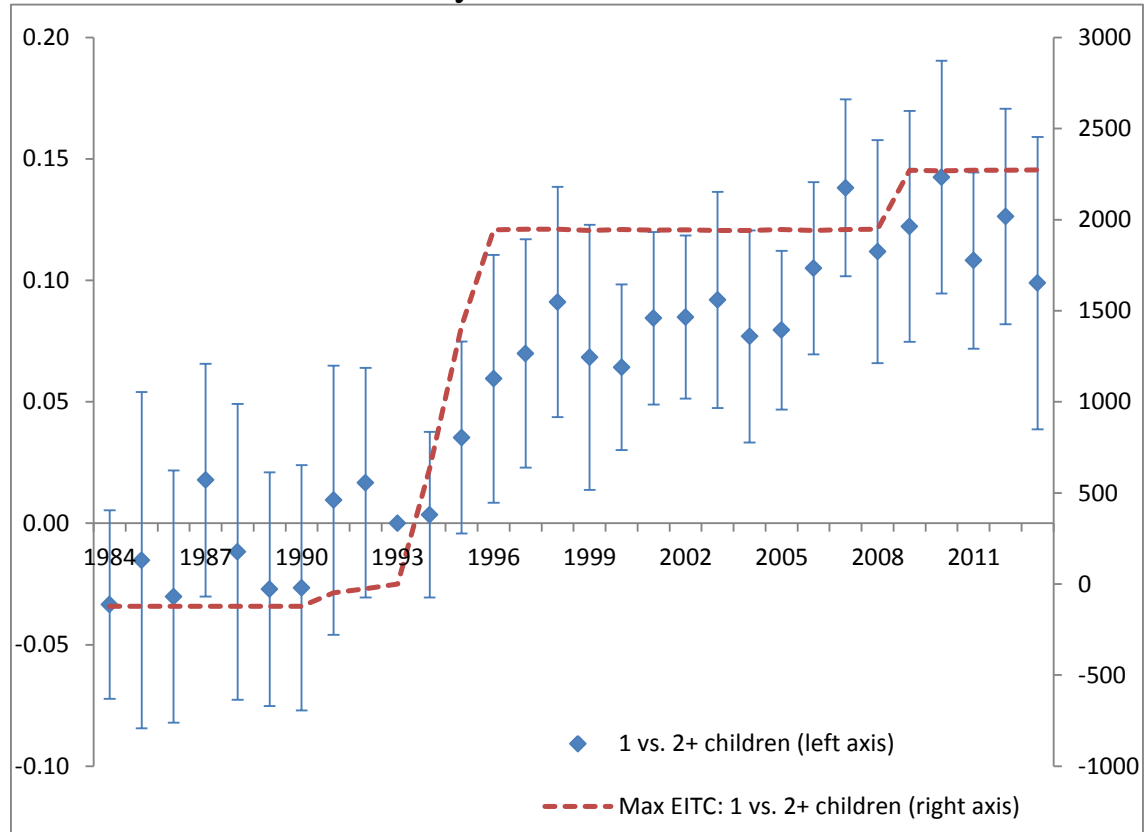

Notes: The sample includes single women with children, ages 24 through 48 with some college education or less from the 1985 through 2014 Current Population Survey (March). See equation (3) in text and data appendix for details. $95 \%$ confidence intervals clustered on state.

Appendix Figure 8: Parameterized DD Estimates of TRA86, OBRA90 and OBRA93 on ATT Income Above Multiples of the Federal Poverty Threshold, 0 vs. 1+ Children, with and without Conservative control set

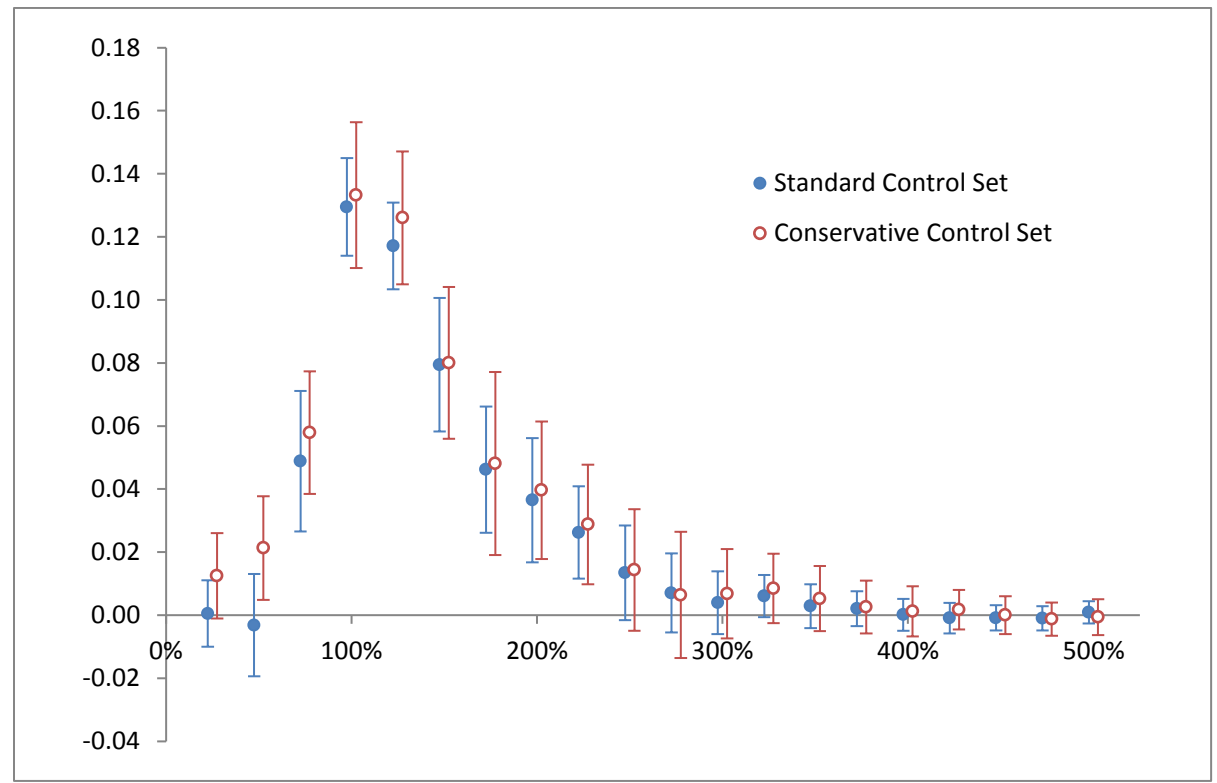

Notes: The sample includes single women, ages 24 through 48 with some college education or less from the 1985 through 1999 Current Population Survey (March). Each dot and whisker represents a single regression estimate and confidence interval. Simulated EITC constructed from 1983 CPS and TAXSIM. See equation (1) in text and data appendix for details. $95 \%$ confidence intervals clustered on state. 


\section{Appendix Table 1: Summary Statistics}

\begin{tabular}{lcc}
\hline & Without children & With children \\
\hline Average age & 34.0 & 34.4 \\
& $(0.1)$ & $(0.1)$ \\
Share with HS degree or more & 0.876 & 0.789 \\
& $(0.006)$ & $(0.010)$ \\
Share white & 0.785 & 0.648 \\
& $(0.016)$ & $(0.027)$ \\
Average number of children & & 1.879 \\
& & $(0.015)$ \\
Share divorced & 0.361 & 0.679 \\
& $(0.014)$ & $(0.012)$ \\
Average federal EITC & $\$ 16$ & $\$ 951$ \\
& $(1)$ & $(38)$ \\
Share employed & 0.892 & 0.776 \\
& $(0.006)$ & $(0.017)$ \\
Average earnings & $\$ 28,722$ & $\$ 22,063$ \\
& $(428)$ & $(367)$ \\
Average after tax and transfer income & $\$ 22,021$ & $\$ 24,042$ \\
& $(259)$ & $(322)$ \\
After tax and transfer income above & 0.741 & 0.571 \\
100\% of poverty line & $(0.007)$ & $(0.008)$ \\
Observations & 48,989 & 47,215 \\
\hline
\end{tabular}

Notes: The sample includes single women, ages 24 through 48 with some college education or less from the 1985 through 1999 Current Population Survey (March). Taxes calculated using the NBER TAXSIM program. Standard errors clustered on state. 
Appendix Table 2: Difference-in-Difference Estimates of OBRA93 on Employment by Education Level

\begin{tabular}{|c|c|c|c|c|}
\hline \multirow{3}{*}{$\begin{array}{l}\text { Model: } \\
(\text { Year > 1993 }) *(1+\text { children })\end{array}$} & \multicolumn{2}{|c|}{0 vs. $1+$ Children } & \multicolumn{2}{|c|}{1 vs. $2+$ Children } \\
\hline & \multicolumn{4}{|c|}{ All education levels } \\
\hline & $\begin{array}{c}0.056^{* * *} * \\
(0.01)\end{array}$ & $\begin{array}{c}0.045^{* * * *} \\
(0.01)\end{array}$ & & \\
\hline$($ Year $>1993) *(2+$ children $)$ & & & $\begin{array}{c}0.057 * * * \\
(0.01)\end{array}$ & $\begin{array}{l}0.019 \\
(0.01)\end{array}$ \\
\hline Per $\$ 1000$ of federal EITC & 0.073 & 0.076 & 0.076 & 0.047 \\
\hline$\%$ impact & $8.4 \%$ & $8.7 \%$ & $9.4 \%$ & $5.8 \%$ \\
\hline Extensive margin elasticity & 0.35 & 0.37 & 0.51 & 0.32 \\
\hline Observations & 67,605 & 67,605 & 28,509 & 28,509 \\
\hline Mean of the dependent variable & 0.872 & 0.872 & 0.813 & 0.813 \\
\hline$($ Year $>1993) *(1+$ children $)$ & $\begin{array}{c}0.062 * * * \\
(0.01)\end{array}$ & $\begin{array}{r}H S g r \\
0.048 * * * \\
(0.01)\end{array}$ & less & \\
\hline$($ Year $>1993) *(2+$ children $)$ & & & $\begin{array}{c}0.073 * * * \\
(0.02)\end{array}$ & $\begin{array}{l}0.022 \\
(0.02)\end{array}$ \\
\hline Per $\$ 1000$ of federal EITC & 0.070 & 0.074 & 0.099 & 0.063 \\
\hline$\%$ impact & $8.8 \%$ & $9.3 \%$ & $13.3 \%$ & $8.6 \%$ \\
\hline Extensive margin elasticity & 0.37 & 0.39 & 0.59 & 0.39 \\
\hline Observations & 30,249 & 30,249 & 16,182 & 16,182 \\
\hline Mean of the dependent variable & 0.793 & 0.793 & 0.742 & 0.742 \\
\hline \multicolumn{5}{|l|}{ Controls } \\
\hline Demographics & $\mathrm{X}$ & $\mathrm{X}$ & $\mathrm{X}$ & $\mathrm{X}$ \\
\hline \# of children indicators & $\mathrm{X}$ & $\mathrm{X}$ & $\mathrm{X}$ & $\mathrm{X}$ \\
\hline State $*$ year indicators & $\mathrm{X}$ & $\mathrm{X}$ & $X$ & $X$ \\
\hline Simulated tax \& transfer benefits & & $\mathrm{X}$ & & $\mathrm{X}$ \\
\hline Any AFDC waiver $* 1+$ children & & $\mathrm{X}$ & & \\
\hline Any AFDC waiver $* 2+$ children & & & & $\mathrm{X}$ \\
\hline Unemp rate $* 1+$ children & & $X$ & & \\
\hline Unemp rate $* 2+$ children & & & & $\mathrm{X}$ \\
\hline
\end{tabular}

Notes: The sample includes single women, ages 24 through 48 from the 1992 through 1999 Current Population Survey (March). See text and data appendix for details. Standard errors clustered on state. Significance levels: *10\%, **5\%,***1\%. 


\section{Appendix Table 3: Parameterized DD Estimates of OBRA93 on Employment (1993 CPS)}

\begin{tabular}{lcccc} 
Model: & \multicolumn{2}{c}{0 vs. 1+ Children } & \multicolumn{2}{c}{1 vs. 2+ Children } \\
\hline Simulated EITC $(\$ 1,000)$ & $0.118^{* * *}$ & $0.106^{* * *}$ & $0.118^{* * *}$ & $0.099 * * *$ \\
& $(0.01)$ & $(0.01)$ & $(0.02)$ & $(0.03)$ \\
Per \$1000 of federal EITC & 0.076 & 0.073 & 0.072 & 0.075 \\
$\%$ impact & $9.0 \%$ & $8.7 \%$ & $9.0 \%$ & $9.4 \%$ \\
Extensive margin elasticity & 0.38 & 0.37 & 0.41 & 0.42 \\
Observations & 50,508 & 50,508 & 25,101 & 25,101 \\
Mean of the dependent variable & 0.844 & 0.844 & 0.796 & 0.796 \\
Controls & & & & $\mathrm{X}$ \\
Demographics & $\mathrm{X}$ & $\mathrm{X}$ & $\mathrm{X}$ & $\mathrm{X}$ \\
\# of children indicators & $\mathrm{X}$ & $\mathrm{X}$ & $\mathrm{X}$ & $\mathrm{X}$ \\
State * year indicators & $\mathrm{X}$ & $\mathrm{X}$ & $\mathrm{X}$ & $\mathrm{X}$ \\
Simulated tax \& transfer benefits & & $\mathrm{X}$ & & $\mathrm{X}$ \\
Any AFDC waiver * $1+$ children & & $\mathrm{X}$ & & $\mathrm{X}$ \\
Any AFDC waiver * $2+$ children & & $\mathrm{X}$ & & \\
Unemp rate * $1+$ children & & & & \\
Unemp rate * $2+$ children & & & & \\
\hline
\end{tabular}

Notes: The sample includes single women, ages 24 through 48 with some college education or less from the 1992 through 1999 Current Population Survey (March). Simulated EITC constructed from 1993 CPS and TAXSIM. See text and data appendix for details. Standard errors clustered on state. Significance levels: $* 10 \%, * * 5 \%, * * * 1 \%$. 